\title{
Monitoring the Effects of Forest Restoration Treatments on Post-Fire Vegetation Recovery with MODIS Multitemporal Data
}

\section{Willem J. D. van Leeuwen}

Department of Geography and Regional Development and the Office of Arid Lands Studies, 1955 E. Sixth Street, The University of Arizona, Tucson, AZ 85721, USA; Tel. +1 5206260058;

Fax +1 5206213816; E-mail: leeuw@ag.arizona.edu

Received: 29 January 2008 / Accepted: 21 March 2008 / Published: 25 March 2008

\begin{abstract}
This study examines how satellite based time-series vegetation greenness data and phenological measurements can be used to monitor and quantify vegetation recovery after wildfire disturbances and examine how pre-fire fuel reduction restoration treatments impact fire severity and impact vegetation recovery trajectories. Pairs of wildfire affected sites and a nearby unburned reference site were chosen to measure the post-disturbance recovery in relation to climate variation. All site pairs were chosen in forested uplands in Arizona and were restricted to the area of the Rodeo-Chediski fire that occurred in 2002. Fuel reduction treatments were performed in 1999 and 2001. The inter-annual and seasonal vegetation dynamics before, during, and after wildfire events can be monitored using a time series of biweekly composited MODIS NDVI (Moderate Resolution Imaging Spectroradiometer - Normalized Difference Vegetation Index) data. Time series analysis methods included difference metrics, smoothing filters, and fitting functions that were applied to extract seasonal and inter-annual change and phenological metrics from the NDVI time series data from 2000 to 2007. Pre- and post-fire Landsat data were used to compute the Normalized Burn Ratio (NBR) and examine burn severity at the selected sites. The phenological metrics (pheno-metrics) included the timing and greenness (i.e. NDVI) for the start, peak and end of the growing season as well as proxy measures for the rate of green-up and senescence and the annual vegetation productivity. Pre-fire fuel reduction treatments resulted in lower fire severity, which reduced annual productivity much less than untreated areas within the Rodeo-Chediski fire perimeter. The seasonal metrics were shown to be useful for estimating the rate of post-fire disturbance recovery and the timing of phenological greenness phases. The use of satellite time series NDVI data and derived pheno-metrics show potential for tracking vegetation cover dynamics and successional
\end{abstract}


changes in response to drought, wildfire disturbances, and forest restoration treatments in fire-suppressed forests.

Keywords: vegetation recovery, phenology, fire severity, fuel reduction treatments, MODIS, LANDSAT.

\section{Introduction}

Recurring drought and wildfire are widespread stressor and disturbance events that affect forest ecosystem functioning and processes and can result in significant soil erosion, and changes in land cover and carbon dynamics. Current climate variability coupled with a buildup of forest fuel loads in the Southwestern US has resulted in an increasing number of large and severe wildfires [1]. However, the effect of fuel reduction treatments on modifying the behavior and effects of wildfires has rarely been evaluated synoptically.

There is therefore a need to develop tools to evaluate post fire recovery trajectories and assess the effectiveness of land management decisions. The use of fire severity and vegetation recovery data, at local, state and national levels, could provide a baseline that can be used to monitor vegetation recovery and the health of fire affected landscapes over time. Fire severity data along with associated biophysical and phenological characteristics provide an analytical basis for assessing future resources, the risks posed by invasive species, and threats to biodiversity.

Monitoring post-disturbance (e.g. fire and landslides) vegetation recovery has been conducted using LANDSAT [2], and AVHRR [3-5] data. The normalized difference vegetation index (NDVI; [6]) is the most commonly used spectral index for regional and continental studies and is sensitive to absorbed photosynthetically active radiation, greenness and gross primary production when integrated over the season [7-12].

$$
\text { NDVI }=\left(\rho_{\text {NIR }}-\rho_{\text {red }}\right) /\left(\rho_{\text {NIR }}+\rho_{\text {red }}\right)
$$

Vegetation condition and recovery before and after fires has been analyzed with the multi-temporal NDVI data [4].

A more spatially explicit and reliable means to map fire severity has been developed using singleand multi-date LANDSAT data utilizing the spectral normalized burn ratio (NBR) index [2, 13, 14], computed as the difference between near-infrared (NIR) and shortwave infrared (SWIR) reflectance ( $\rho$ ) divided by their sum [15]:

$$
\operatorname{NBR}=\left(\rho_{\text {NIR }}-\rho_{\text {SWIR }}\right) /\left(\rho_{\text {NIR }}+\rho_{\text {SWIR }}\right)
$$

The difference between a pre-fire NBR and a post-fire NBR is also often used to classify the spatial distribution of fire severity $[16,17]$ :

$$
\Delta \mathrm{NBR}=\mathrm{NBR}_{\text {pre-fire }}-\mathrm{NBR}_{\text {post-fire }}
$$

\subsection{Vegetation Trends, Seasonality, Disturbance, Anomalies and Noise}

Time-series NDVI satellite data is a valuable resource to detect trends, seasonality and anomalies in forest vegetation dynamics that are changing due to climate change, drought, management activities 
(e.g. fuel treatments), and wildfires. However, to successfully model the trends and seasonality of the time series data, noise in NDVI values often need to be reduced by smoothing the data and making use of accompanying quality assurance and metadata.

Vegetation recovery rates have been calculated from Landsat data based on the relationship between the NDVI and time [18]. The ratios between the mean NDVI of burned and unburned areas have been used to estimate post-fire recovery based on a number of Landsat scenes [19, 20].

Disturbance events like wildfire cause changes in the spatial heterogeneity of the landscape mosaic which is important for ecosystem processes and management that impacts biodiversity as the landscape adapts to and recovers from repeat wildfire events. The standard deviation of the NDVI for a particular study site is dependent on scale, land cover type [21], seasonality, disturbance regime, and time since the disturbance took place. The coefficient of variance (COV=Standard deviation/Mean) can be used to characterize spatial heterogeneity, and has the advantage that it normalizes for the change in the mean value of the NDVI for each site. For example, the COV was used to [22] characterize the temporal spatial heterogeneity dynamics in Northeast Brazil due to persistent drought episodes and desertification in Saudi Arabia [23].

Monitoring land surface phenology or the timing of vegetation growth stages and events is important for understanding pre- and post-wildfire vegetation growth trends and seasonality and land cover change that may result from management intervention or from climate variability and change. Phenological studies are regarded as an important means of understanding many phenomena that are related to land cover and land use change caused by disturbances such as drought and wildfires. Remote sensing-based monitoring of phenology has utilized high temporal frequency reflectance data from the heritage Advanced Very High Resolution Radiometer (AVHRR) and the current NASA Moderate Resolution Imaging Spectroradiometer (MODIS). In this study we explore a novel approach to the use of phenological metrics as a tool to monitor the impact of fuel reduction treatments on the trends and seasonality during recovery of vegetation after a wildfire event.

Most studies utilizing remote sensing phenology analyze data on the basis of the satellite-based vegetation indices (e.g. NDVI). However, more recently research has focused on the derivation of phenological metrics from these indices. These pheno-metrics are most often based on observing, modeling, and identifying critical times (e.g. timing of start, peak, length of the growing season, amounts of greenness) in the yearly seasonal vegetation index (VI) that correspond to phenological phases of vegetation growth. Multiple algorithms have been designed to retrieve the timing and magnitude of vegetation phenological phases based on statistical measures of the rate of changing values or slope of the NDVI signature on a pixel-by-pixel basis. Reed et al. [24] grouped the approaches into three categories: 1) based on thresholds like the half maximum NDVI [25, 26], 2) based on inflection points [27, 28], and 3) based on curve derivatives like delayed moving average and time of maximum increase [29-31]. Jönsson and Eklundh, [32, 33] designed an approach that is a hybrid between the threshold and curve derivative methods. Because some of these methods indicate significant differences between their results [24], it is important to consistently apply one method if multiple sites are being compared. 


\subsection{Post-wildfire vegetation recovery research objectives}

Fuel reduction treatments decrease fire hazards caused by forest fuel accumulations and less frequent low severity fires [34]. The goal of this research is to develop post-fire vegetation recovery monitoring tools using satellite derived pheno-metrics to inform fuel treatment management decisions and evaluate their effectiveness. To accomplish this, several vegetation recovery monitoring techniques are explored. The primary objectives of this research are therefore to:

- Examine how pre-fire fuel reduction treatments impact fire severity and vegetation recovery trajectories.

- Evaluate if simple NDVI time-series metrics such as difference from average and cross site seasonality ratios are useful to characterize the effectiveness of fuel reduction treatments on vegetation recovery.

- Characterize pre- and post-wildfire seasonal vegetation dynamics using seasonal and interannual remotely sensed phenological signatures and metrics.

Because of the unpredictability of the timing and location of wildfire events, this research effort is based on a unique coincidence of fuel reduction treatment management activities and a large catastrophic fire event. The random nature of these events does not generally facilitate carefully designed sampling protocols that allow for many years of field data collection before and after the fire and treatments. Hence, the focus of this study is on the development of geospatio-temporal tools and technology to evaluate and monitor the effect of forest restoration treatments on post-fire vegetation recovery that require limited field observations.

\section{Study area}

Arizona, located in the US southwest, is characterized by forested mountain ranges, expansive valleys and deep canyons producing a wide range of vegetation cover from desert cacti and shrub grasslands to riparian areas and coniferous forests. Within this mosaic, the Rodeo-Chediski wildfire started on June 18th, 2002 and burned for several weeks. It was the largest wildfire in Arizona history, and by the time the fires were contained on July 7th, the fire had burned a total of 186,373 ha of mostly forest land on the Ft. Apache reservation (60\%), Apache-Sitgreaves National forest (36\%), Tonto National forest $(2 \%)$ and private land $(2 \%)$. The fire perimeter is shown in Figure 1. Approximately $\$ 250$ million in timber was destroyed or damaged by the fire. Erosion and sedimentation threaten three important fisheries because rains that followed the wildfire caused a significant increase in erosion. The Salt River turned black from the ash in the runoff, in spite of hay and grass seeds having been spread post-fire to stabilize the soil and generate vegetation.

For Arizona, 2002 was one of the driest years on record based on winter-spring precipitation data for 1896 to 2002 and can be compared to the droughts of 1972 and 1904 . Figure 2 shows the precipitation data for a long term 30-year average (1960-1990) and the below average precipitation data for the last eight years (Monsoon data for 2007 is not yet available). Spring precipitation in 2002 was anomalously low. The average monthly maximum temperature in June and July is about $30^{\circ} \mathrm{C}$. The average monthly minimum temperature in December, January and February is about $-5^{\circ} \mathrm{C}$. The average difference between monthly maximum and minimum temperature is about $16^{\circ} \mathrm{C}$. 
Figure 1. General location of the study area in Arizona and the position of the RodeoChediski burn perimeter

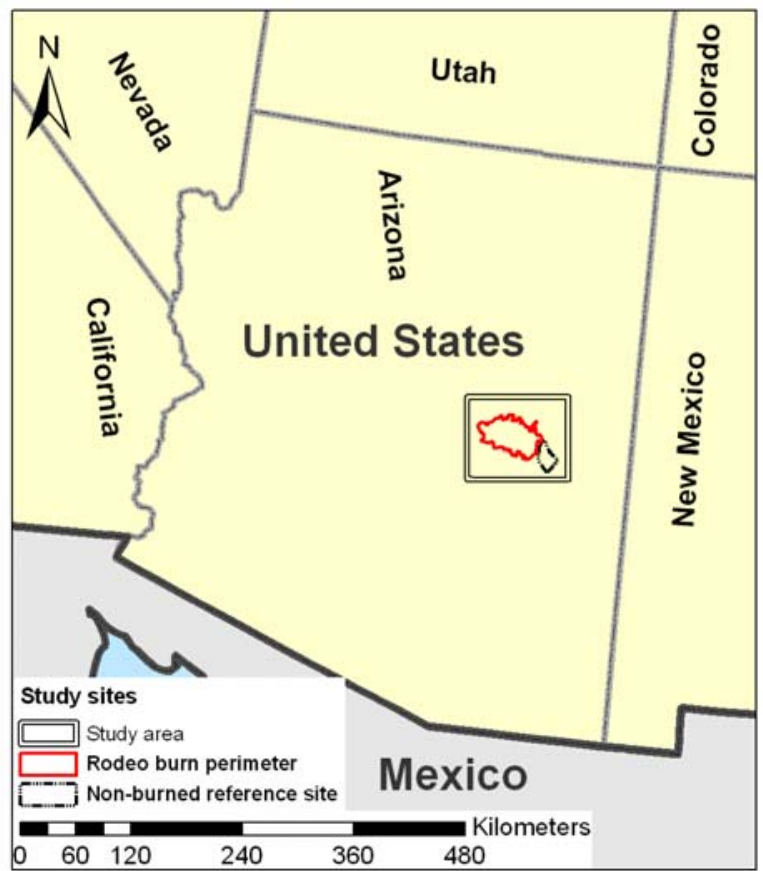

Figure 2. Annual mean cumulative spring (Jan.-June) and monsoon (July-Dec.) precipitation data showing the drop in precipitation in 2002.

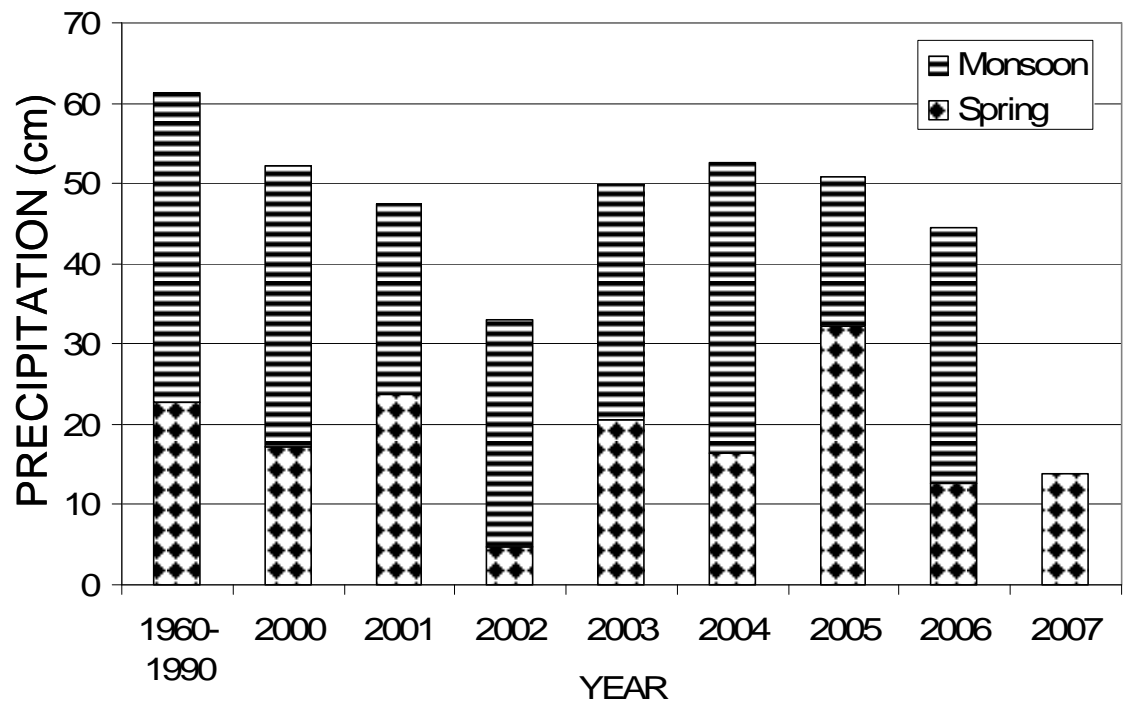

\section{Data and Methods}

\subsection{Fuel reduction treatment, burned and reference site selection}

The experimental sampling design was based on the concurrence of prescribed burn treatments, the 2002 Rodeo-Chediski fire complex and the availability of satellite data records at the time of the fire. The location of the study area and samples included the area within the 2002 Rodeo-Chediski burn perimeter, two areas with fuel treatments in 1999 and 2001, an untreated area that burned in 2002 
similar in size to the treatment areas, and an unburned reference site adjacent to the Rodeo-Chediski burn perimeter (Figure 3). Pre-fire vegetation types of the fuel treatment sites, burned areas and reference sites are dominated by Ponderosa Pine as shown by the Southwest Regional Gap Analysis map (SWReGAP [35]; Figure 3). The SWReGap map is based on field assessments and Landsat data that were acquired between 1999 and 2001 and has a spatial resolution of 30 meters per pixel.

Selection of the fuel reduction treatment sites was based on data from Finney et al. [2]. This research focused on two sites with the most recently prescribed fire treatments that were conducted in 1999 and 2001 by the US Forest Service on Apache-Sitgreaves National Forest. These relatively recent treatment sites were chosen because the MODIS NDVI data record starts in 2000. A more detailed description of management activities is described by Finney et al. [2].

Figure 3. Study sites and land cover classification map based on SWReGAP [35].The study sites are dominated by Ponderosa pine and some Madrean pine oak.

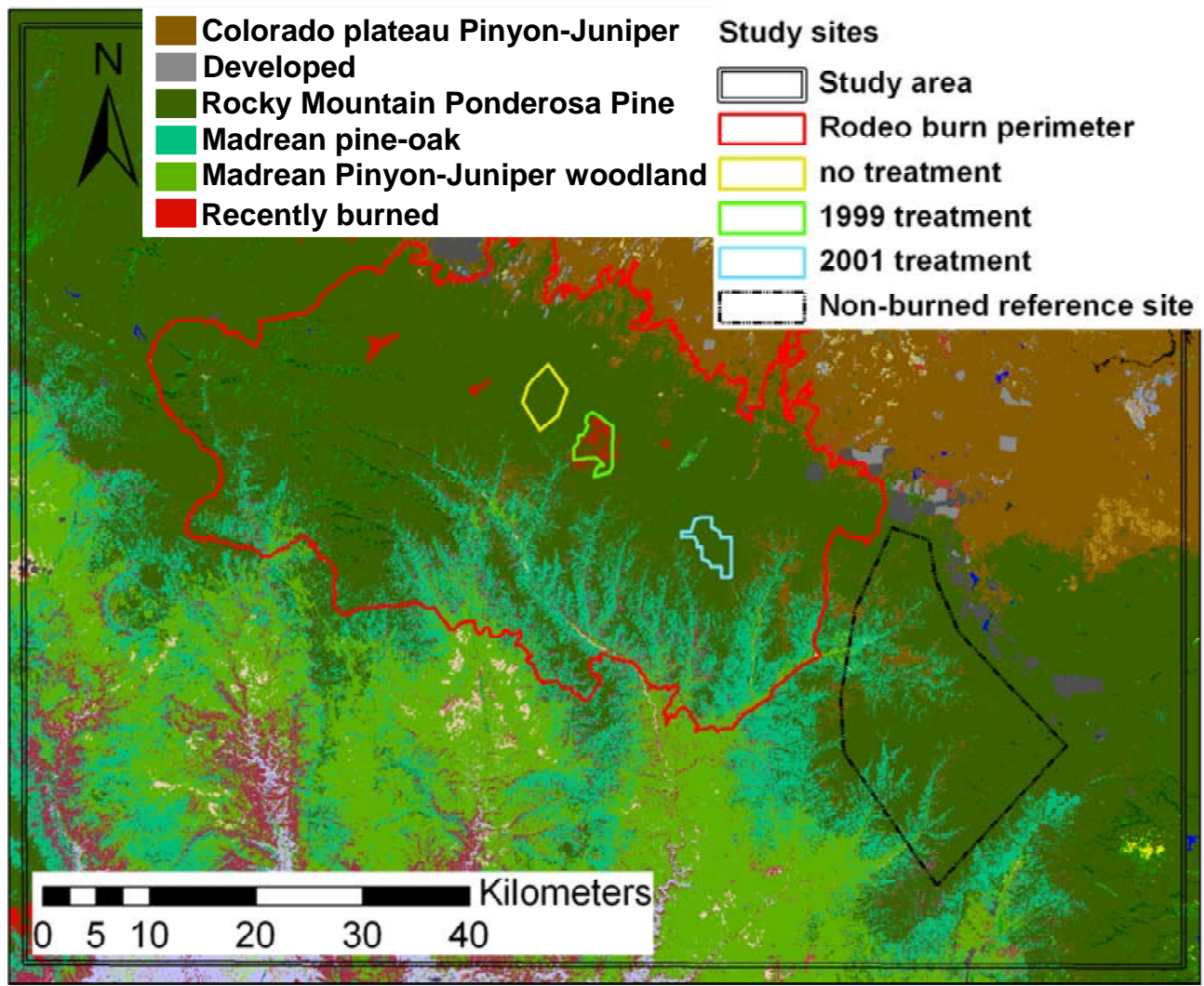

\subsection{Landsat data}

Subsets of pre-fire and one post-fire Landsat 7 Enhanced Thematic Mapper plus (ETM+) images at 30$\mathrm{m}$ resolution were provided by the National Park Service - US Geological Survey Burn Severity Mapping Project (http://burnseverity.cr.usgs.gov/) [36] and were terrain corrected and calibrated to atsatellite reflectance data. The Differenced Normalized Burn Ratio $(\triangle N B R)$ protocol is applied to infer the burn severity and examine the effects of the fire on vegetation mortality immediately after the fire [37]. The burn severity map derived from the pair of Landsat images was also used to examine the effect of fuel treatments on post fire vegetation recovery. 
Figure 4. MODIS NDVI time series imagery for the selected study sites are shown for August (2001) and June (2002) before the Rodeo-Chediski fire showing relatively high NDVI values for the study sites. Low NDVI values are observed for the August (2002) right after the fire, with the NDVI gradually increasing in the August images for 2003, 2005 and 2007.

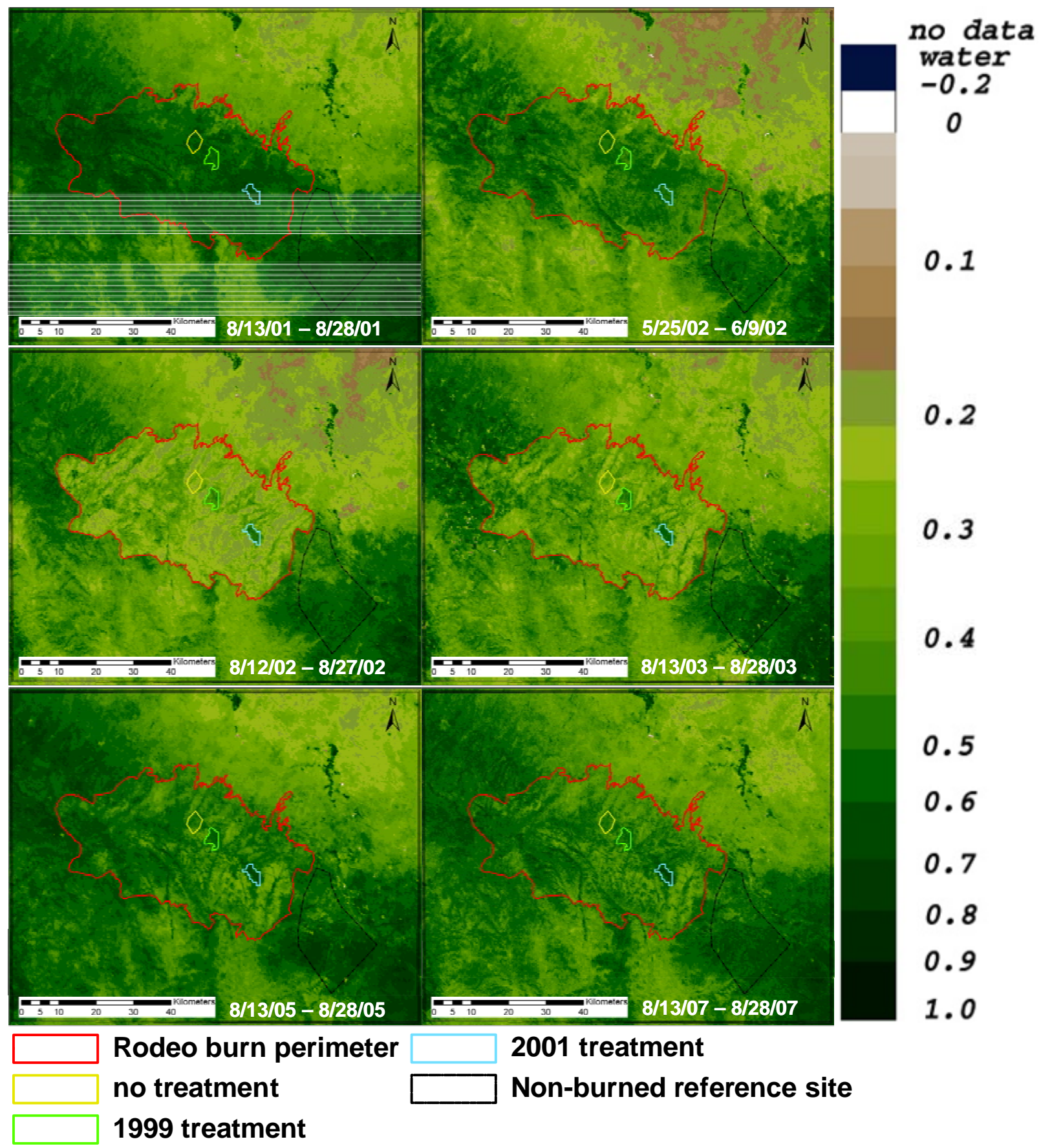

\subsection{MODIS data}

NDVI data from the Moderate Imaging Spectroradiometer (MODIS) on the Terra satellite was used for the NDVI time series analysis. Examples of the NDVI data before and after the fire are shown in Figure 4. MODIS data from March 2000 through December 2007 were obtained for the study area in central Arizona. The MODIS NDVI data and associated quality assurance (QA) data at $250 \mathrm{~m}$ 
resolution and 16-day composite intervals were used in this research. This resulted in 23 composite NDVI and QA images (periods) per year. The data were downloaded from the Land Processes Distributed Active Archive Center in Sioux Falls, SD, USA, and mosaicked and re-projected into Lambert Azimuthal equal area projections suitable for analysis. This resulted in a time-series of 179 NDVI and QA images. The mean of the NDVI time-series data were extracted for all areas of interest excluding pixels that were affected by clouds or snow based on the QA data. These data provided the basis for examining the trends, seasonality and anomalies in the NDVI and the associated phenometrics for the treatment, burned and non-burned reference areas.

\subsection{Vegetation phenology}

Figure 5. An example of the phenological metrics that are retrieved based on time series (blue curve) of 16-day composites of MODIS NDVI data for Ponderosa pine land cover and TIMESAT software [33]. The brown line is the fitted curve with the brown circles indicating the start and end of the growing seasons.

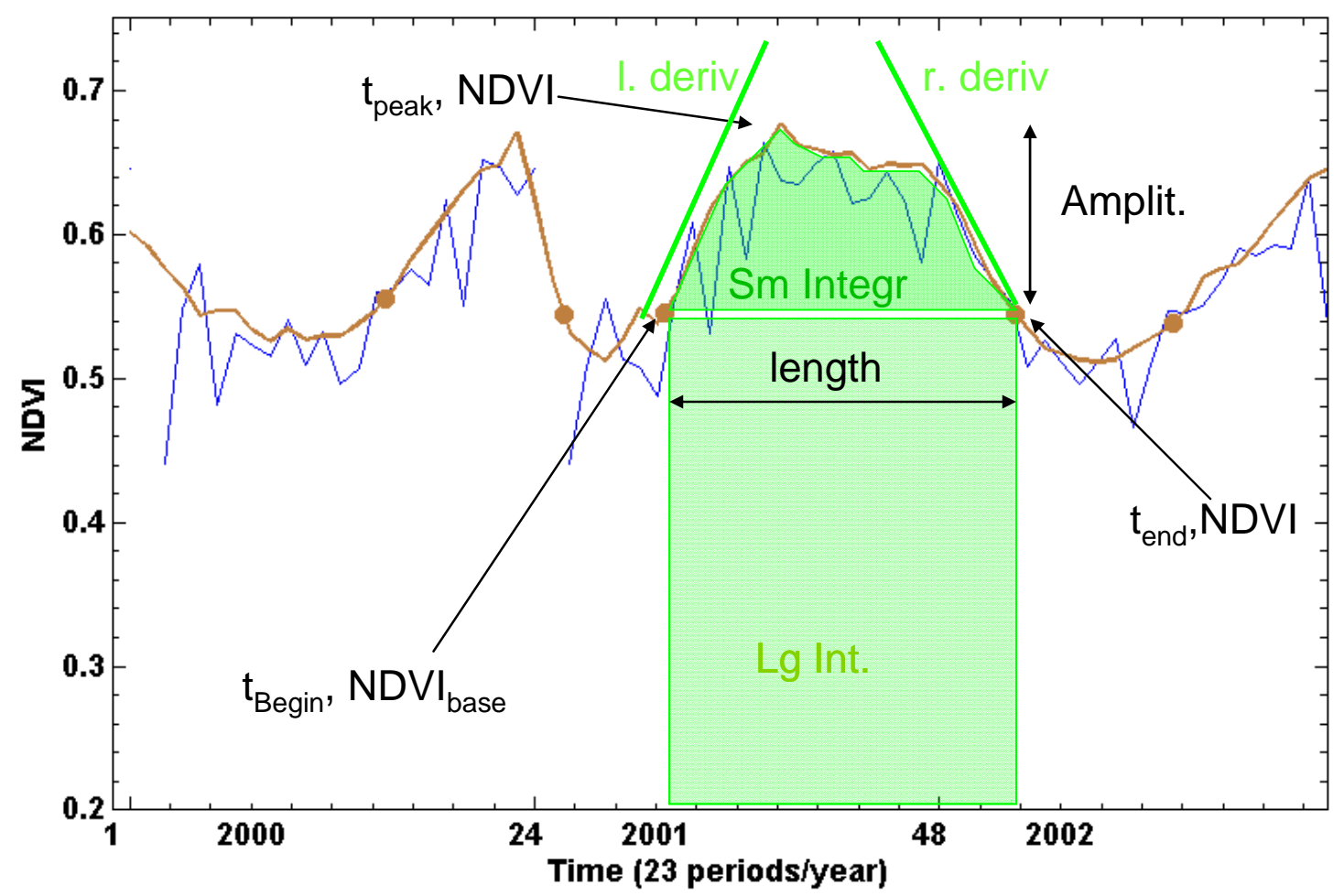

MODIS NDVI based phenological metrics (pheno-metrics) were calculated yearly to evaluate the impact of prescribed burn treatments on post-wildfire vegetation recovery. Vegetation phenology metrics of the treatment sites, burned sites and non-burned reference site were derived by applying a local (the window size is set to 3 observations) second-order polynomial function also known as an adaptive Savitzky-Golay filter as described by Jönsson and Eklundh [32, 33]. The annual phenometrics for all sites were compared and analyzed to examine if they can be used to monitor and assess post-wildfire vegetation recovery. The pheno-metrics for each of the growing seasons that are included in the analysis are depicted in Figure 5. The beginning of a season, marked by $t_{\text {begin }}$ in the 
figure, is defined by the fitted functions as the point in time for which the value has increased by $20 \%$ of the distance between the left minimum NDVI value and the maximum NDVI value. The end of the season $t_{\text {end }}$ is defined similarly. The peak of a season is estimated by the position $t_{\text {peak }}$ for which the $\mathrm{NDVI}_{\text {peak }}$ value of the fitted function has increased to $80 \%$ of the distance between the left and right minimum $\mathrm{NDVI}_{\text {base }}$ values and the maximum NDVI value. The amplitude (Amplit.) of the season is obtained as the difference between the peak NDVI value and the average of the left and right minimum NDVI values. The length of season is computed as the difference between the end and beginning of the growing season. The first integral (Sm Integr), given by the area of the region between the fitted function and the average NDVI values of the left and right minima, represents the seasonally active vegetation, which may be large for herbaceous vegetation cover and small for evergreen vegetation cover. The second integral ( $L g I n t)$, given by the area of the region between the fitted function and the zero NDVI value, represents the total vegetation production. The left derivative or rate of increase in NDVI ( $l$. deriv) during the beginning of the growing season is related to the rate of green-up and plant growth and can be estimated by calculating the ratio between the amplitude and the time difference between the start and midpoint of the growing season. The right derivative (r.deriv) is related to the rate of senescence, but is also governed by snow cover that can obscure green vegetation from being observed by the satellite sensor. Different vegetation cover types are likely to have different rates of green-up and green-down.

\subsection{Time series analysis}

Drought and wildfire disturbance events can cause abrupt changes in the trend and seasonality of vegetation growth cycles or phenology as sites recover and often appear as anomalies in annual and seasonal vegetation growth trajectories. Pre-fire and post-fire trends and anomalies for all sites were evaluated by 1) examining and computing the post-fire seasonal trends in NDVI of the long term seasonal average time-series data; 2) analyzing the seasonal differences between average NDVI values and NDVI values for each year, 3) computing the ratio between average seasonal reference NDVI values and the seasonal NDVI values of the treatment and burned areas to evaluate difference in seasonality between the sites, and 4) determining the trends in change of site spatial heterogeneity based on the median COV values for each year. Changes in post-fire NDVI values for each site were compared by evaluating the inter-annual trends for each season starting after 2002, the year of the Rodeo-Chediski fire.

The post-fire NDVI time-series data for the treatment, burned and reference areas were evaluated by computing a simple linear post-fire recovery regression model based on the 5 years (112 MODIS composite periods) of NDVI data after the fire. For each site this model can be expressed as:

$$
\mathrm{NDVI}_{\text {time }}=\text { a time }+b
$$

where time is expressed as 16-day composite periods. It is expected that positive trends or slopes $(a)$ are associated with the rate of vegetation cover increase or post-fire recovery, and that intercept $(b)$ values will be higher for treated sites and healthy forest condition than for burned sites. A similar model (4) is also applied to the $\mathrm{NDVI}_{\text {base }}$ and $\mathrm{NDVI}_{\text {peak }}$ pheno-metrics. The time variables are based on the corresponding $t_{\text {base, sos }}$ and $t_{\text {peak }}$ inter-annual composite times using the first composite period of 2003 as the base value (i.e. time $=1$ ) 
To detect site specific vegetation cover anomalies due to wildfire in the seasonal trajectories of the burned, treatment and control or reference sites, the seasonal differences between average NDVI values (2000-2006) and NDVI values for each year were calculated as:

$$
\Delta \mathrm{NDVI}_{\text {time, average }}=\mathrm{NDVI}_{\text {current, time }}-\mathrm{NDVI}_{\text {average, time }}
$$

This difference metric can be used to monitor the timing and spatial extent of the fires and provide insight into the post-fire vegetation response.

The seasonal differences were evaluated by calculating the ratio of the NDVI time series for each site and the NDVI time series data of the reference or control site:

$$
\text { Seasonality } \text { Ratio }_{\text {time }}=\mathrm{NDVI}_{\text {time, }} \text { site } / \mathrm{NDVI}_{\text {time, }} \text { reference site }
$$

The seasonality Ratio (SR) of each of the sites was expected to change after the fire due to successional changes in species compositions and soil properties like nutrient availability, hydrofobicity and erosion. If the seasonality of each of the sites is not in sync with the control site, it is expected that this ratio will show the differences in seasonal cycles.

It was expected that pre-fire spatial patchiness or heterogeneity would be lower than post-fire spatial heterogeneity when vegetation re-growth was affected by fire severity and its spatial pattern. Spatial heterogeneity is likely to decrease with increasing vegetation recovery over time. The median COV for each year and site was determined based on the time-series of the spatial aggregated NDVI data for each 16-day composite period.

Finally, MODIS time-series NDVI data were summarized for each of the burned and reference sites by calculating the earlier described eleven pheno-metrics for each year. The TIMESAT software used [33] requires a consistent number of observations per year and a certain window size to compute the local curve fits. Three values that were missing from the time-series in the beginning of the year 2000 were replaced by zero values of NDVI, making some of the computed metrics for the year 2000 (start of the season, left derivative, integrals) unsuitable for incorporation in the analysis. To compute the moving local fitting functions and pheno-metrics for the year 2007, one year of seasonal average NDVI values were padded at the end of the actual time series data, making some of the computed metrics for the year 2007 (end of the season, right derivative, integrals) also less suitable for incorporation in the analysis. Most years had one or two missing values due to consistent snow or cloud cover, but the algorithm interpolated for those observations in the time series data. Ultimately, this resulted in a total of eight years of pheno-metrics for each of the sites. Pheno-metrics were compared between the reference, treatment and burned sites to evaluate their ability to characterize differences in trends and seasonality between the sites. The rates of change for each site and phenometric were evaluated beginning in the year after the Rodeo-Chediski fire. The left and right derivatives were divided to evaluate the skewness between the strength of the green-up at the start and senescence rate at the end of the growing season.

\section{Results and Discussion}

\subsection{Landsat Derived $\triangle N B R$ for the study sites}

The fire impacted the treated and untreated areas differently as can be seen in the color composites in Figure 6. The pre- and post-fire RGB color composites using bands 7, 4, and 3 provide a quick and 
qualitative indication that the treated, pre-fire and reference areas show up in green and the untreated burned areas in red colors.

Figure 6. Pre- and post-fire RGB (ETM bands 7, 4, and 3) color composites for June 5, 2002 and July 7, 2002, respectively. The Rodeo-Chediski fire was on June 18, 2002. The selected sites and fire perimeter are indicated as well. Some clouds and their shadows are visible in the Northeast side of the burn perimeter in the post-fire scene.
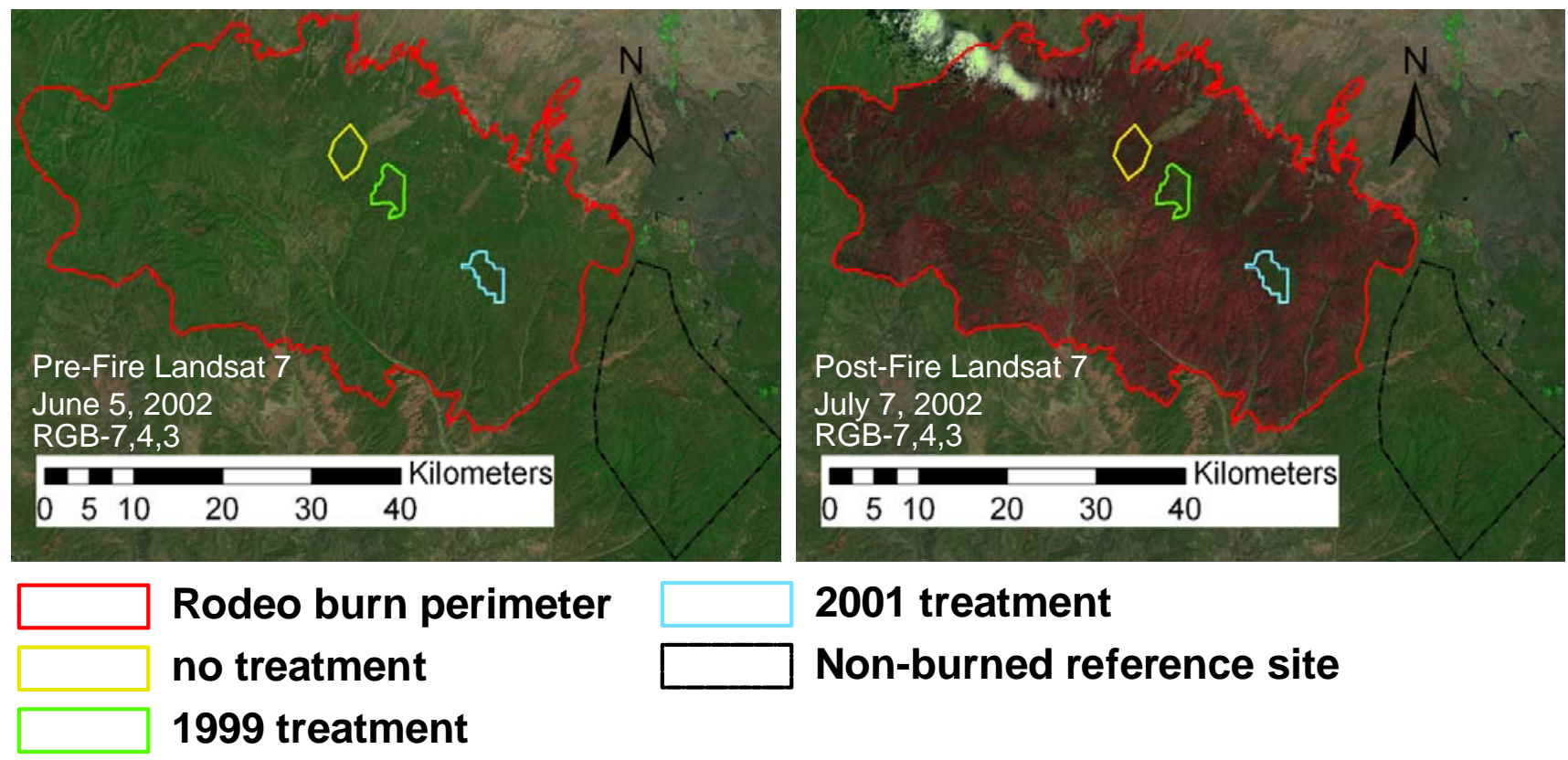

\section{Rodeo burn perimeter no treatment 1999 treatment}

\section{1 treatment}

Non-burned reference site

Figure 7 shows forest conditions in 2004 after the ground fire or low severity fire went through the site (left) leaving many trees alive. The crown fire with left-over snags or high severity (right) fire devastated large parts of Apache-Sitgreaves National forest. Herbaceous vegetation cover appeared in its place.

Figure 7. Examples of the effect of low severity (left) and high severity (right) fires on sites inside Apache-Sitgreaves National Forest. Fuel reduction treatments (thinning) were applied at the site displayed in the picture to the left. Pictures taken in May, 2004.
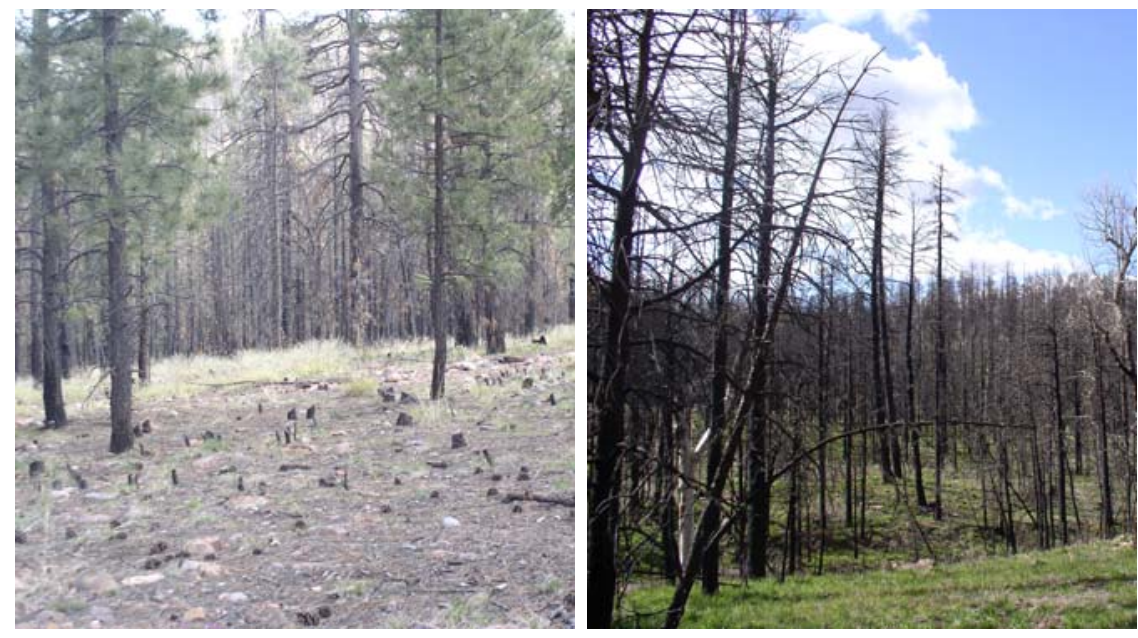
The pair of Landsat scenes (Figure 6) and classified derived $\triangle$ NBR image (Figure 8) from the Rodeo-Chediski fires provide very clear evidence of landscape level effects of prescribed fire fuel treatments in these southwestern ponderosa pine forests [2]. The $\triangle$ NBR based burn severity classes for the 1999 and 2001 treatment sites were predominantly "Unburned" and indicated that some areas burned at "Low severity". Fire severity for the untreated site was mostly moderate but included limited areas of low (ground fire) and high severity (crown fires). The reference site was classified predominately as "Unburned". These results are consistent with research that showed that fuel treatment reduces fire severity in ponderosa pine forests $[38,39]$. The $\Delta$ NBR data suggest complex and spatially heterogeneous patterns of fire severity within the Rodeo-Chediski fire perimeter that are related to fuel treatments, but also to roads, drainages and topography. These initial results provide impetus for more detailed analyses of the ecological relationships between these patterns and variables.

Figure 8. Locations of the 1999 and 2001 prescribed fire treatments on Apache-Sitgreaves National Forest lands reveal that the fire mostly avoided the two treatment areas. Burn severity for the entire study area, including the reference site and Rodeo-Chediski fire area, was classified based on the $\triangle$ NBR that was derived from the pre-fire image acquired on 5 June 2002, and the post-fire image acquired on 7 July 2002 . Values of $\triangle$ NBR were classified into five fire severity categories (adapted from [37]) based on $\triangle \mathrm{NBR}$ ranges that correspond with visible indications of fire damage to understory and tree foliage and crowns: Regrowth $(\triangle \mathrm{NBR}<-100$, Unburned ($100 \leq \Delta \mathrm{NBR}<100)$, Low severity $(100 \leq \Delta \mathrm{NBR}<270$, ground fire; foliage still green), Moderate severity $(270 \leq \triangle \mathrm{NBR}<550$, green and brown foliage with significant foliage consumed by fire), and High severity $(\triangle \mathrm{NBR}>550$, crown fire; complete consumption of foliage). Fire severity was reduced greatly within treatment units (outlined with light green and blue polygons).
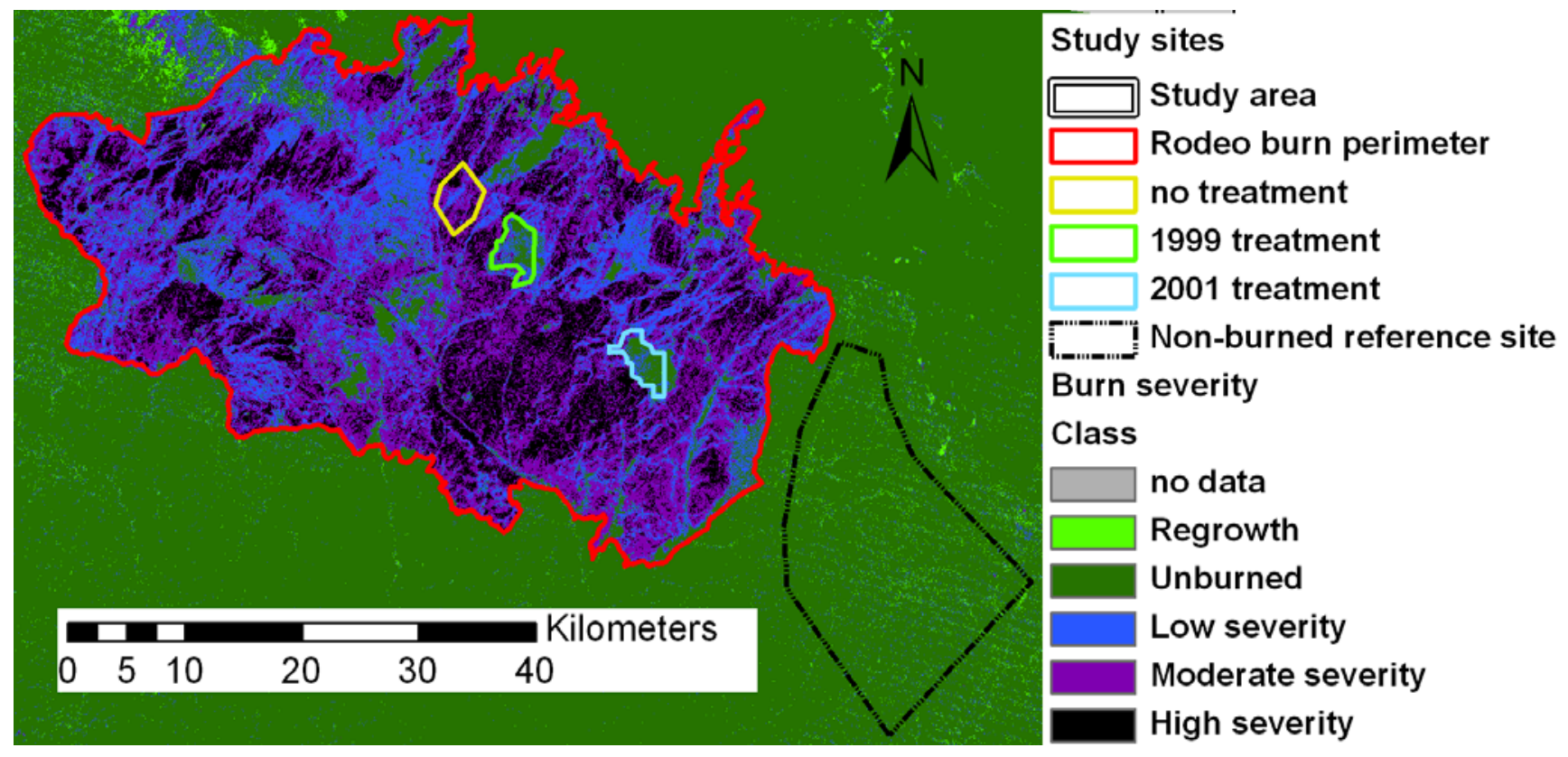
Figure 9. MODIS NDVI times series data for all composite periods of 2000-2007. Seasonality and an abrupt decrease in the NDVI are seen for all sites except the unburned reference site. The NDVI for the complete Rodeo-Chediski (RC) area drops the most. The results of the post-fire linear regression vegetation recovery model are shown for years 2003 through 2007.

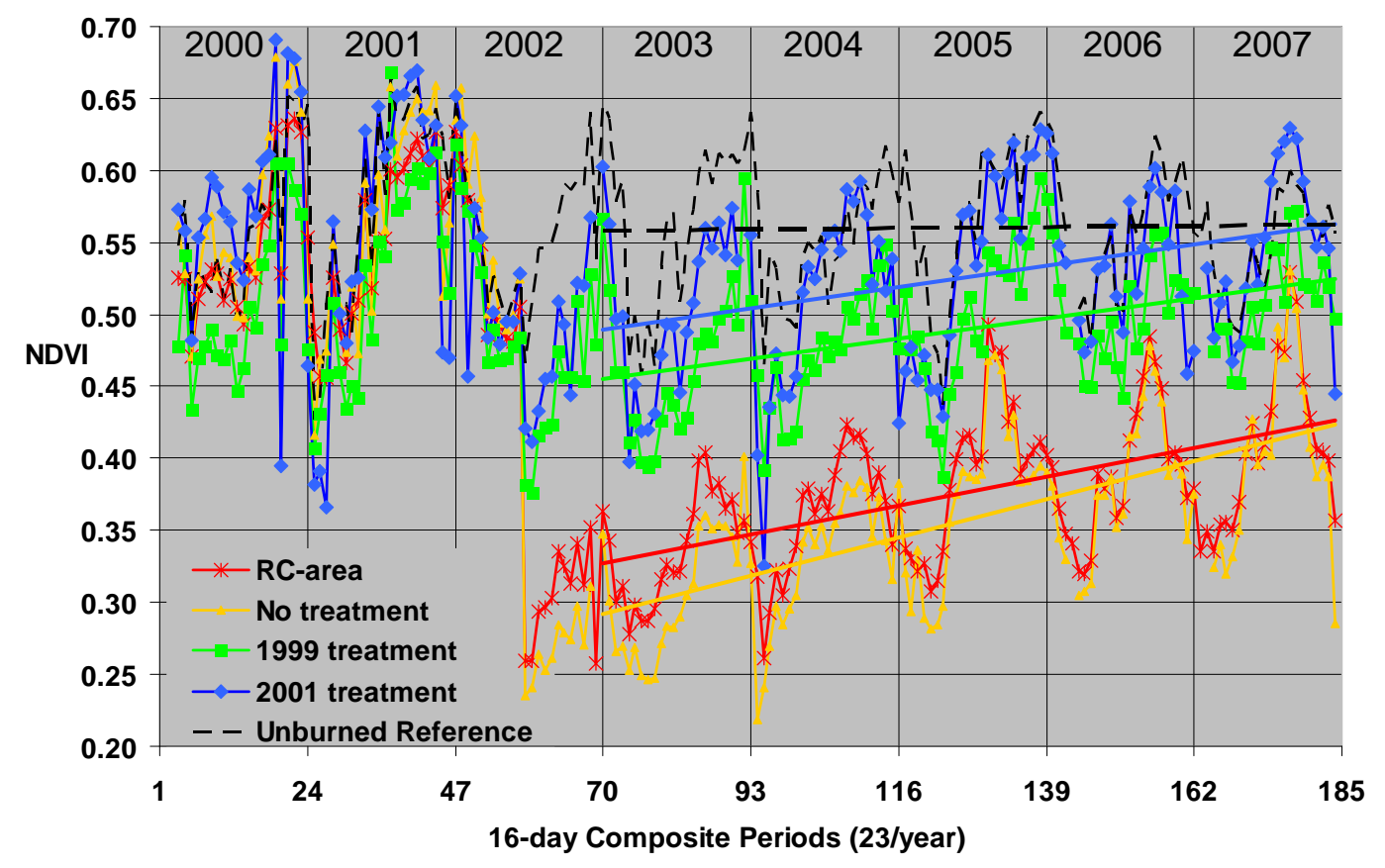

\subsection{Trends and Seasonality of Vegetation Recovery}

Pre-fire NDVI seasonality signatures are shown in Figure 9 for all sites from year 2000 up until the RC fire in June 2002. Although some seasonal differences can be observed among the sites, their NDVI trajectories are similar before the fire. Post fire NDVI values, trends and seasonality are shown to change considerably among the Rodeo-Chediski, treatment and reference sites (Figure 9). Visually, the post-fire times of the start, peak and end of the growing seasons vary among the sites, indicating differences in response to the burn severity level and possibly to changes in species composition. Table 1 shows the post-fire recovery results based on the linear vegetation recovery models. The postfire recovery modeling results show that the values of the slopes and intercepts for all sites are significantly different from each other. The reference site is very stable and shows a recovery rate close to zero with the highest NDVI intercept. The 1999 and 2001 treatment sites both show reduced NDVI intercepts, suggesting that the vegetation cover was reduced due to low intensity ground fire or because of reduced vegetation health and cover after the surrounding area burned. The NDVI values for the 2001 treatment site are returning to their pre-fire level and are close to the control site NDVI values. The post-fire vegetation recovery rates are very similar for both the 1999 and 2001 treatment sites. The rate of post-fire vegetation recovery for the untreated site is higher than that of the RodeoChediski-area. The 1999 and 2001 treatment sites have higher NDVI intercepts than both the notreatment site and Rodeo-Chediski-area, suggesting that the treatments were effective in avoiding high severity fire. The rate of vegetation recovery for both the untreated site and Rodeo-Chediski-area are higher than both the 1999 and 2001 treatment sites, suggesting that the treatments caused less severe fires and different vegetation recovery and succession processes among the sites. P-values indicate that 
all recovery rate and intercept values are significant. Recovery rates can be multiplied by 23 to get the change in NDVI per year.

Table 1. Results for the vegetation recovery regression analysis for the treatment, reference and burned sites - vegetation recovery rates, intercepts and associated p-values $(95 \%$ confidence level) are based on post-fire NDVI data from 2003 to 2007.

\begin{tabular}{lcccc}
\hline \multirow{2}{*}{ Site } & \multicolumn{2}{c}{ Recovery rate (a) } & \multicolumn{2}{c}{ Intercept (b) } \\
& Slope & p-value & Intercept & p-value \\
\hline RC-area & 0.00086599 & $1.70565 \mathrm{E}-10$ & 0.2666 & $7.96301 \mathrm{E}-32$ \\
No-treatment & 0.00114690 & $6.79382 \mathrm{E}-13$ & 0.2099 & $4.49369 \mathrm{E}-20$ \\
$\mathbf{1 9 9 9}$ treatment & 0.00067454 & $8.09505 \mathrm{E}-08$ & 0.4022 & $6.25667 \mathrm{E}-49$ \\
2001 treatment & 0.00069845 & $3.04318 \mathrm{E}-05$ & 0.4355 & $1.35798 \mathrm{E}-39$ \\
Reference & 0.00010719 & 0.424174251 & 0.5447 & $2.74426 \mathrm{E}-56$ \\
\hline
\end{tabular}

Site specific vegetation cover anomalies due to wildfire are observed in the seasonal trajectories of the burned and treatment sites while the reference site shows variation that matches the 7-year average (Figure 10). To correctly interpret the difference from average results it is necessary to take the historical environmental context into account and the time of the fire event. Figure 10 shows that fire affected areas have a sharp decline due to the fire event, but also shows the gradual recovery towards the site NDVI average. The yearly seasonal patterns change variably from year to year and from site to site. The reference site shows some variation in seasonality if we, for example, compare year 2001 with year 2004. In this case year 2001 generally had above average NDVI values, while year 2004 had NDVI values that were very close to zero or below average.

Although pre-fire variation in the NDVI profiles between the five sites can be observed, the general profiles are similar and all close to each other in the spring of 2002 (Figure 11). The post-fire seasonal ratio values for all sites not only show the large reduction in the relative NDVI magnitude values in comparison with the reference site, the seasonality shows signs of change for most sites as well. The 1999 treatment site seems to be for the most part in phase with the unburned reference site because the ratio profile has little sigmoid behavior. The seasonality ratio for the 2001 treatment site shows variable sigmoid response. On the other hand the post-fire seasonality patterns of the burned sites are very much out of phase with the reference site, especially from 2004 forward, suggesting that the sequence of vegetation changes in the post fire succession of plant communities are different through time for the treated and burned sites. Depending on among others, the burn severity and fire return interval, the post disturbance sequence of species that dominate a vegetation community type can range between grass-forbs, saplings and shrubs, resprouting species (e.g Oak), and mature forests. The seasonality ratio sequences suggest that the treated sites maintain a vegetation community that is more similar to the unburned sites than the burned sites. 
Figure 10. MODIS NDVI difference from long term NDVI average times series data for all composite periods of 2000-2007. The NDVI for the Rodeo-Chediski (RC) area and untreated area drop the most, while the reference site show little variation around the mean. Most extreme variation in this metric occurs during winter time, suggesting that sub-pixel clouds and snow covered pixels have not been compensated for completely.

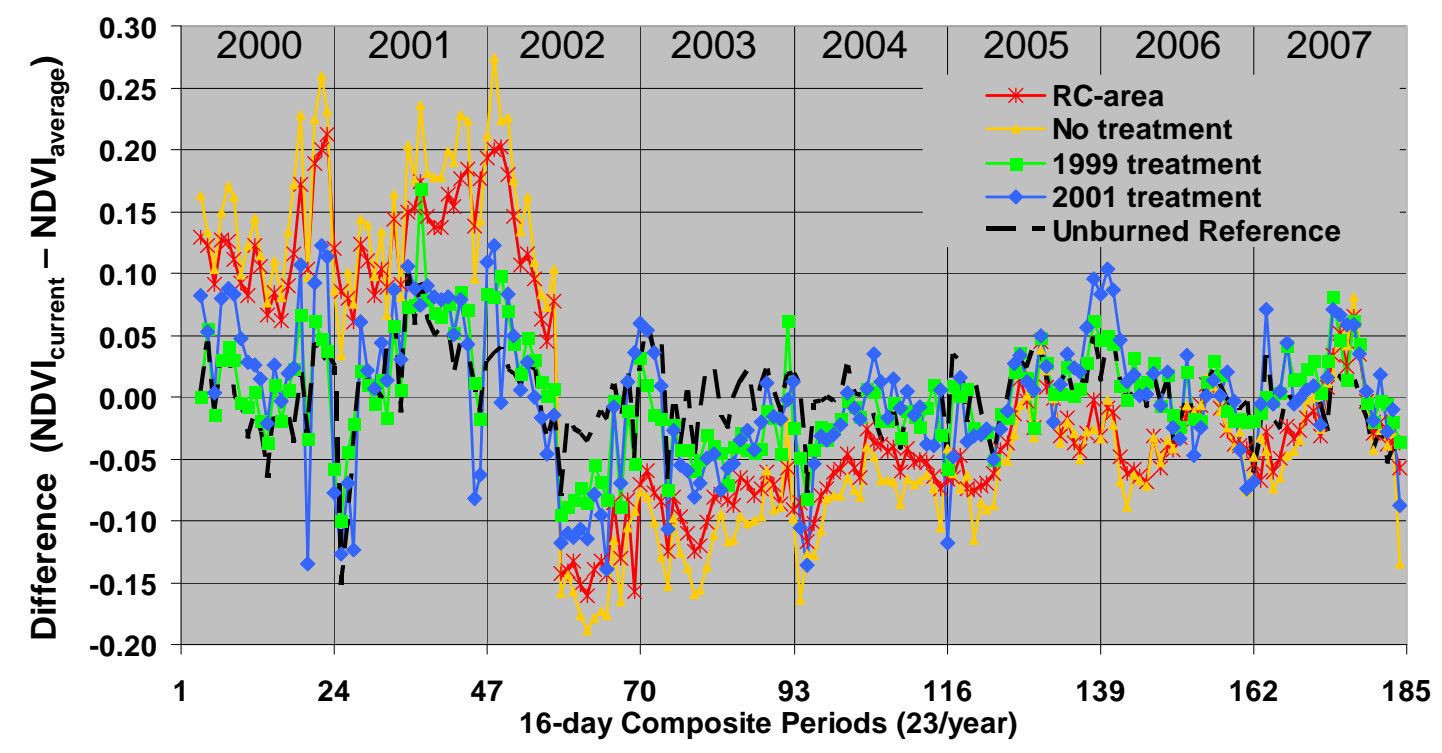

Figure 11. The ratio between unburned seasonal reference site NDVI values and the seasonal NDVI values of the1999 and 2001 treated and burned sites show the difference in seasonality using the reference site as the base values.

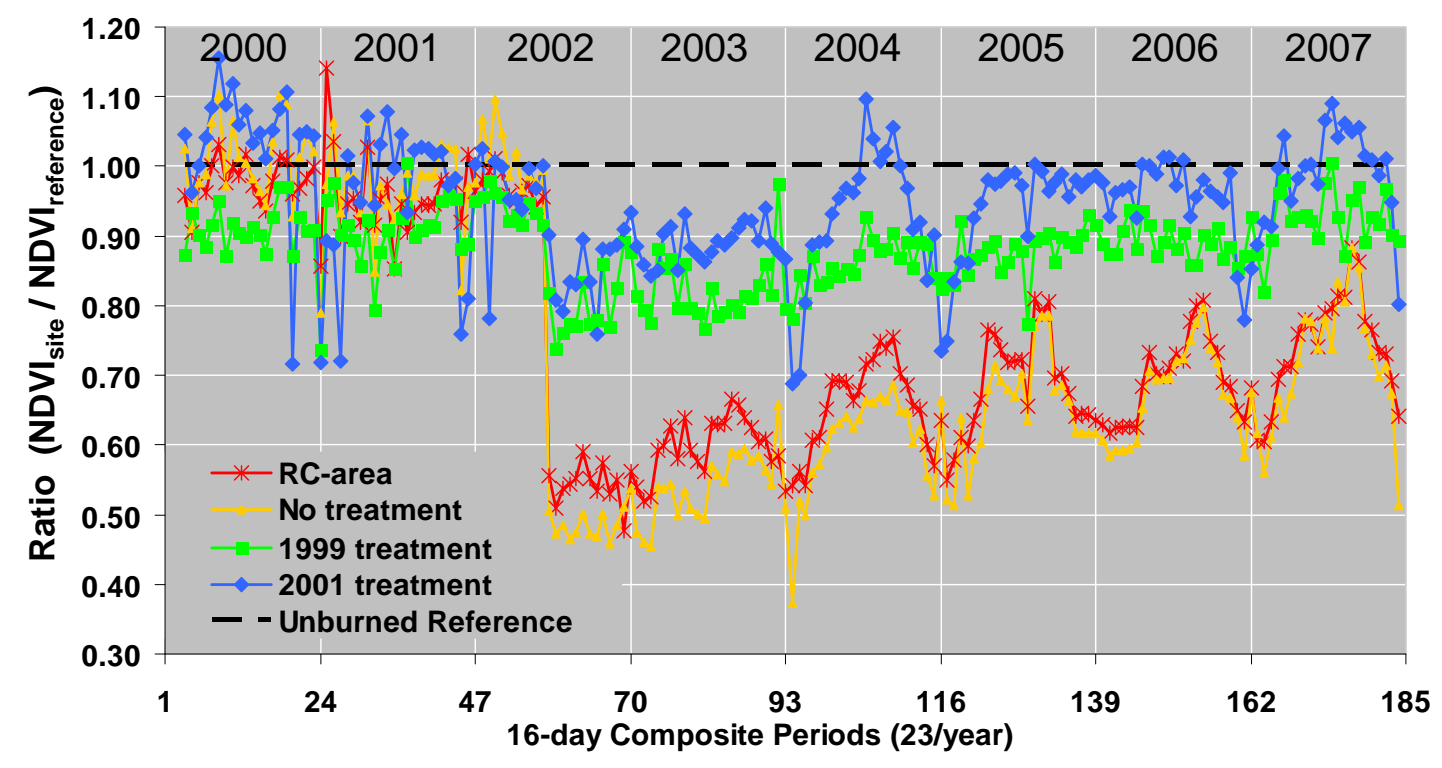

Figure 12 shows the yearly patterns of COV values, suggesting that the spatial heterogeneity or patchiness is highest during the year when the wildfire occurred. The COV values for the unburned reference site remain fairly stable at the same level for all years. All sites within the burn perimeter have lower COV values for the years (2000 and 2001) before the fire. The COV dramatically increased during 2002 and gradually decreased with time after the fire. The 1999 and 2001 treatment sites 
showed the least increase in COV because the impact of the fire was minimal as can be seen by the burn severity levels which were classified as unburned and low severity (Figure 8).

Figure 12. The yearly median COV values are a measure of the relative changes in spatial heterogeneity for the five sites. The COV values peak during the wildfire event (year 2002) and decrease gradually during the years after the fire.

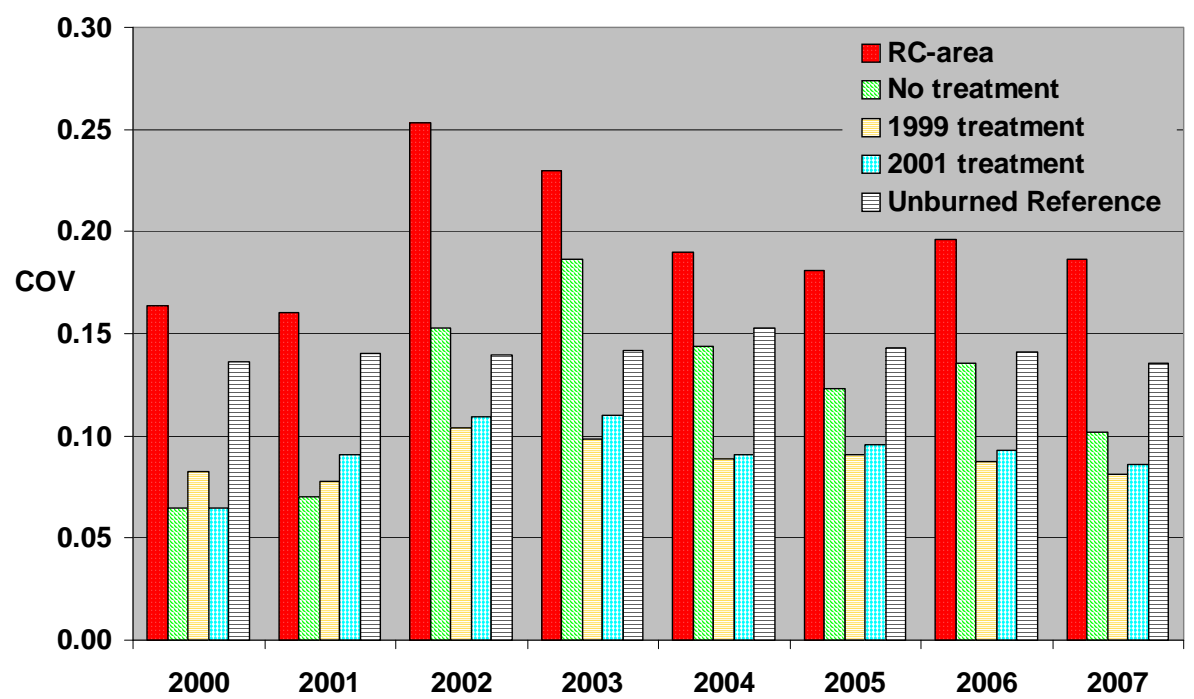

\subsection{Phenological characterization of vegetation trends and seasonality}

Figure 13a shows the inter-annual variability for the start of the growing season (SOS) among the sites. The start of the growing season for the no-treatment site and 2001 treatment sites show late winter green-up (around Day of Year (DOY) 60), while for other years the start of the growing seasons are during the Spring (between DOY 130 and 150). The Rodeo-Chediski area's onset of green-up was also earlier in 2001 and 2004 compared to other years. Adequate winter and spring precipitation in 2001 and 2004 are likely contributors to the early start of the growing seasons. The start of the growing season in 2002 was extremely late for the treatment sites and unburned reference site due to the significant drop in precipitation. Because of the continuing decline in NDVI throughout the winter and spring and during the fire, the SOS, POS and LOS are not retrieved for the severely burned sites in 2002, suggesting that there was no identifiable growing season during that year.

Before 2002, the timing of the peak NDVI value of the growing season (POS) generally occurs at the end of the year or beginning of the calendar year for all sites (Figure 13b). However the post-fire POS values for the burned sites have generally been earlier than the treatment and reference sites, suggesting that the burned sites reach their peak greenness earlier than the treatment sites and reference site.

Because of the drought in 2002 the length of the growing season in 2001 is extremely long for all fire affected sites and lasted close to 500 days, well into 2002 (Figure 13c). Although drought and wildfire are the cause of these LOS retrievals, the extraction algorithm does not discriminate the end of season correctly. The reference site on the other hand shows some consistency for all the years and had the shortest growing season during the 2002 drought. The post-fire LOS values in 2003 for the fire affected sites are lower than the LOS value for the reference site. In 2004 and 2005 the LOS values of 
the fire affected sites are about the LOS values of the reference site, while the LOS values of the fire affected sites in 2006 are generally lower than the reference site again. It is suggested that this variability in LOS is likely due to the start of the snow season, seasonal precipitation distribution and enhanced nutrient availability after the fire event.

Figure 13. Phenological timing metrics are shown for each site and each year for which the data was available and reliable. a) SOS - Start of Season, b) POS - Peak of season and c) LOS - Length of season.

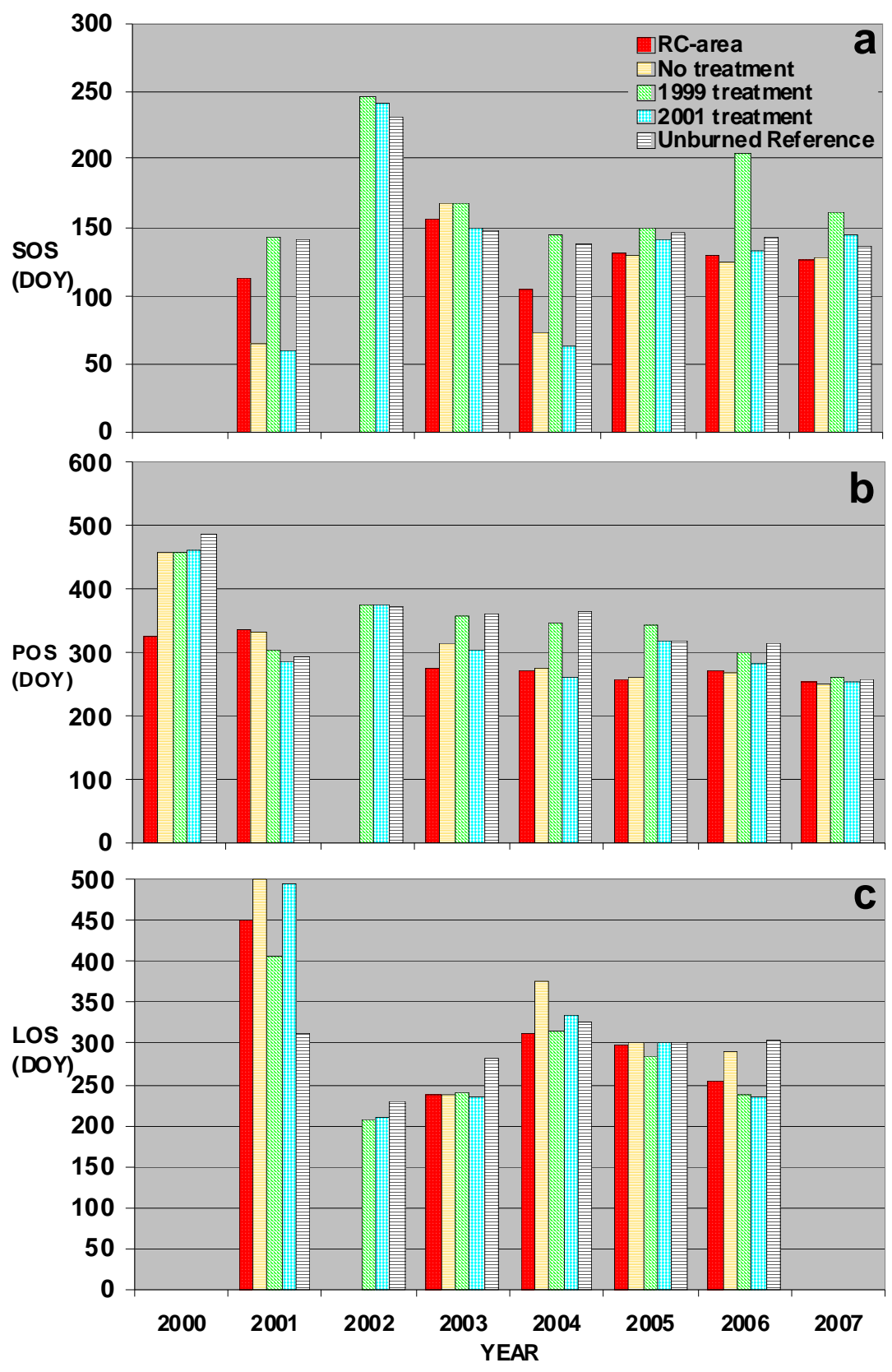

The NDVI $I_{\text {base }}$ values for the reference site are fairly consistent across the years (2000-2007) and higher compared to all the fire affected sites (Figure 14a). Interestingly, the $\mathrm{NDVI}_{\text {base }}$ values for the 1999 and 2001 treatment sites gradually increased after the fire. NDVI $_{\text {base }}$ values for the RC and notreatment sites are higher in 2001 than the post-fire $\mathrm{NDVI}_{\text {base }}$ values, especially right after the fire. 


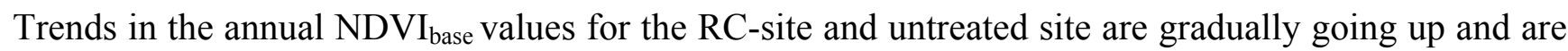
almost back to pre-fire NDVI ${ }_{\text {base }}$ values in 2007.

Pre-fire $\mathrm{NDVI}_{\text {peak }}$ values are higher than the post-fire NDVI $\mathrm{I}_{\text {peak }}$ values for all sites. Both the 2002 drought and wildfire events are likely contributing to this change (Figure 14b). However, the NDVI $I_{\text {peak }}$ values for the 1999 and 2001 treatment sites do not change greatly after the fire, but are much higher than the $\mathrm{NDVI}_{\text {peak }}$ values for the RC-area and untreated sites. The trends in the annual $\mathrm{NDVI}_{\text {peak }}$ values for the RC-site and untreated site are gradually going up and are closing the gap with the post-fire $\mathrm{NDVI}_{\text {base }}$ values of the reference site.

Figure 14. Phenological NDVI based metrics are shown for each site and each year for which the data was available. a) NDVI base values, b) NDVI Peak values, and c) Amplitude (NDVI units).
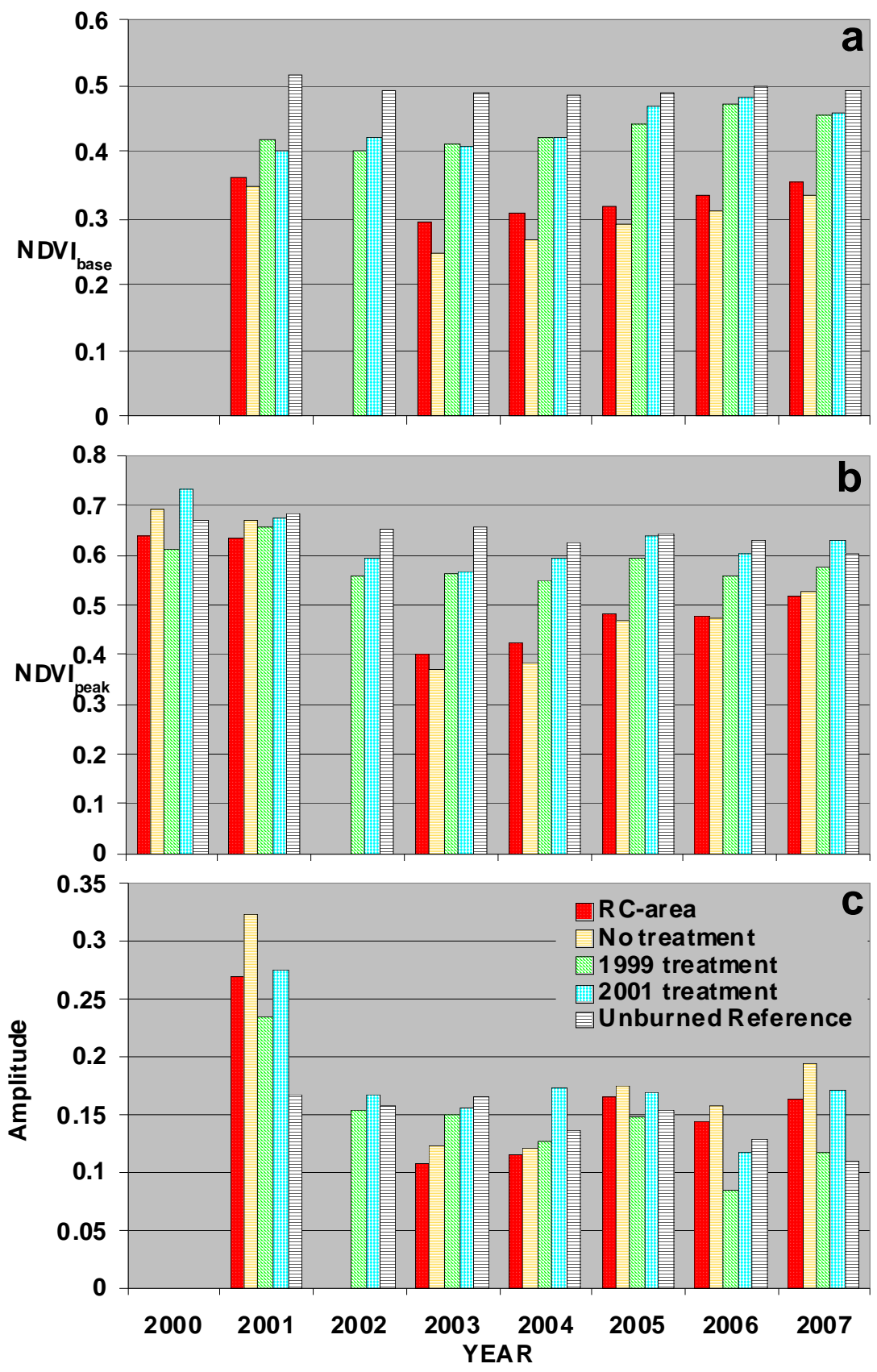
The very high amplitude values in year 2001 for all but the reference site are largely due to the fact that the NDVI $\mathrm{I}_{\text {base }}$ values dropped considerably in 2002, which is seen as the end of the 2001 growing season (Figure 14c). Although drought and wildfire are the cause of these low NDVI observations, the extraction algorithm does not discriminate the end of the season correctly. The wildfire not only caused this extremely long season (Figure 14c) but also a very high amplitude for the fire affected sites (Figure 14c). Although a significant amount of variation exists among the fire affected sites and the reference site, the trends seems to indicate that the amplitude for the fire affected sites are lower the year after the fire (2003) and gradually increase and are higher than the reference site amplitude values in 2007.

Table 2 and Figure 15 show the post-fire recovery results based on the linear vegetation recovery models applied to the inter-annual $\mathrm{NDVI}_{\text {base }}$ and $\mathrm{NDVI}_{\text {peak }}$ phenological metrics and associated $\mathrm{t}_{\text {base, }}$ sos, and $t_{\text {peak }}$ values. Average pre-fire $\mathrm{NDVI}_{\text {base }}$ and $\mathrm{NDVI}_{\text {peak }}$ values are generally higher than the postfire and post-drought values (Table 2). Recovery rates and intercepts derived from the $\mathrm{NDVI}_{\text {base }}$ and $\mathrm{NDVI}_{\text {peak }}$ values (Table 2; Figure 15) are consistent with the trend analysis results obtained form the time series NDVI data analysis presented in Table 1 and Figure 9. For both the NDVI $\mathrm{base}_{\text {and }}$ $\mathrm{NDVI}_{\text {peak }}$ values, the post-fire recovery modeling results show that the values of the recovery slopes and intercepts are significantly different from each other. Based on the $\mathrm{NDVI}_{\text {base }}$ results, the reference site is very stable and shows a vegetation recovery rate close to zero with the highest NDVI intercept. On the other hand, the $\mathrm{NDVI}_{\text {peak }}$ modeling results produce a slightly negative vegetation recovery slope for the reference site. The 1999 and 2001 treatment sites both show that the post-fire NDVI $\mathrm{I}_{\text {base }}$ intercept levels are similar to pre-fire $\mathrm{NDVI}_{\text {base }}$ levels, however the post-fire $\mathrm{NDVI}_{\text {peak }}$ intercept levels are significantly lower than the pre-fire $\mathrm{NDVI}_{\text {peak }}$ values, suggesting that the vegetation cover was lower for the peak of the growing season the year after the fire and within the context of the drought. The rate of post-fire vegetation recovery for the untreated site is higher than that of the Rodeo-

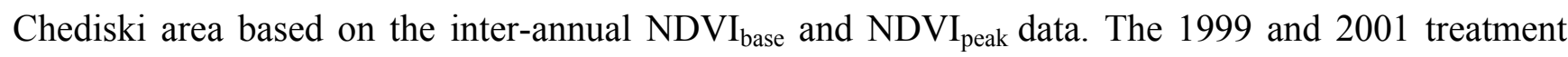
sites have higher $\mathrm{NDVI}_{\text {base }}$ and $\mathrm{NDVI}_{\text {peak }}$ intercepts than both the no-treatment site and RC-area. The rates of vegetation recovery for both the untreated site and RC-area are higher than both the 1999 and 2001 treatment sites, suggesting that the treatments result in less severe fires and different vegetation recovery and succession processes among the sites. P-values indicate that all recovery rate and intercept values are significant. The low $\mathrm{R}^{2}$ value for the linear $\mathrm{NDVI}_{\text {peak }} 1999$ treatment site data fit is very low, but could be improved with a curvilinear model. Reasons for this response could be due to the availability of additional nutrient after the fire and the distribution of rainfall in the spring and monsoon of 2004 and 2005. Again, recovery rates can be multiplied by 23 (periods/year) to calculate the annual change in post-fire NDVI.

Once more, the phenological metrics for the fire affected sites shown in Figure 16 were somewhat anomalous for 2001 due to the extremely long growing season that was identified by the automated curve fitting software. No growing season was detected in 2002 by this algorithm for the RodeoChediski site and no-treatment site. The inter-annual behavior of the small integral for all sites seems to be similar to the precipitation levels as can be seen in Figures 16a and 2 respectively. The small integral values are low in 2002, but go up for the higher precipitation years (2003, 2004 and 2005) and go down again for 2006 and 2007. This suggests that the small integral is increasing with higher precipitation levels. It is evident that the small integral value for the reference site in 2001 was higher 
than the small integral value for the reference site in 2002 due to the low precipitation in 2002 . Differences among small integral values for all sites are not especially distinct.

Table 2. Results for the vegetation recovery regression analysis for the treated, reference, and burned sites. Vegetation recovery rates, intercepts, associated p-values $(95 \%$ confidence level) and $\mathrm{R}^{2}$ are based on post-fire $\mathrm{NDVI}_{\text {base }}$ and $\mathrm{NDVI}_{\text {peak }}$ data from 2003 to 2007. The average pre-fire $\mathrm{NDVI}_{\text {base }}$ and $\mathrm{NDVI}_{\text {peak }}$ values are presented as well.

\begin{tabular}{|c|c|c|c|c|c|c|}
\hline \multirow[t]{2}{*}{ Site } & \multirow{2}{*}{$\begin{array}{c}\text { Pre-fire } \\
\text { NDVI }_{\text {base }}\end{array}$} & \multicolumn{2}{|c|}{ Post-fire Recovery Rate (a) } & \multicolumn{2}{|c|}{ Post-fire Intercept (b) } & \multirow[b]{2}{*}{$\mathbf{R}^{2}$} \\
\hline & & a (NDVI base$)$ & p-value & b (NDVI base $)$ & p-value & \\
\hline RC-area & 0.3637 & 0.0008513 & $2.336 \mathrm{E}-06$ & 0.2878 & 0.002934 & 0.98 \\
\hline No-treatment & 0.3465 & 0.0009486 & $1.12 \mathrm{E}-05$ & 0.2398 & 0.000700 & 0.99 \\
\hline 1999 treatment & 0.4209 & 0.0006022 & 0.000173 & 0.4080 & 0.011312 & 0.80 \\
\hline 2001 treatment & 0.4005 & 0.0007014 & 0.000291 & 0.4111 & 0.018388 & 0.66 \\
\hline \multirow[t]{2}{*}{ Reference } & 0.5145 & $9.48752 \mathrm{E}-05$ & $6.55 \mathrm{E}-05$ & 0.4864 & 0.004171 & 0.41 \\
\hline & NDVI $_{\text {peak }}$ & a (NDVI peak $)$ & p-value & b (NDVI peak $)$ & p-value & $\mathbf{R}^{2}$ \\
\hline RC-area & 0.6357 & 0.0012731 & 0.009922 & 0.3816 & 0.000142 & 0.92 \\
\hline No-treatment & 0.6795 & 0.0017886 & 0.000277 & 0.3313 & 0.019513 & 0.93 \\
\hline 1999 treatment & 0.6341 & 0.0001507 & 0.000274 & 0.5573 & 0.019967 & 0.09 \\
\hline 2001 treatment & 0.7028 & 0.0006086 & 0.000318 & 0.5675 & 0.022653 & 0.55 \\
\hline Reference & 0.6764 & -0.0004613 & 0.000201 & 0.6610 & 0.014631 & 0.64 \\
\hline
\end{tabular}

Figure 15. Post-fire vegetation recovery results based on the linear vegetation recovery models applied to the inter-annual $\mathrm{NDVI}_{\text {base }}$ (left side) and $\mathrm{NDVI}_{\text {peak }}$ (right side) phenological metrics and associated times, time base, $_{\text {sos }}$ and time peak $_{\text {values. }}$
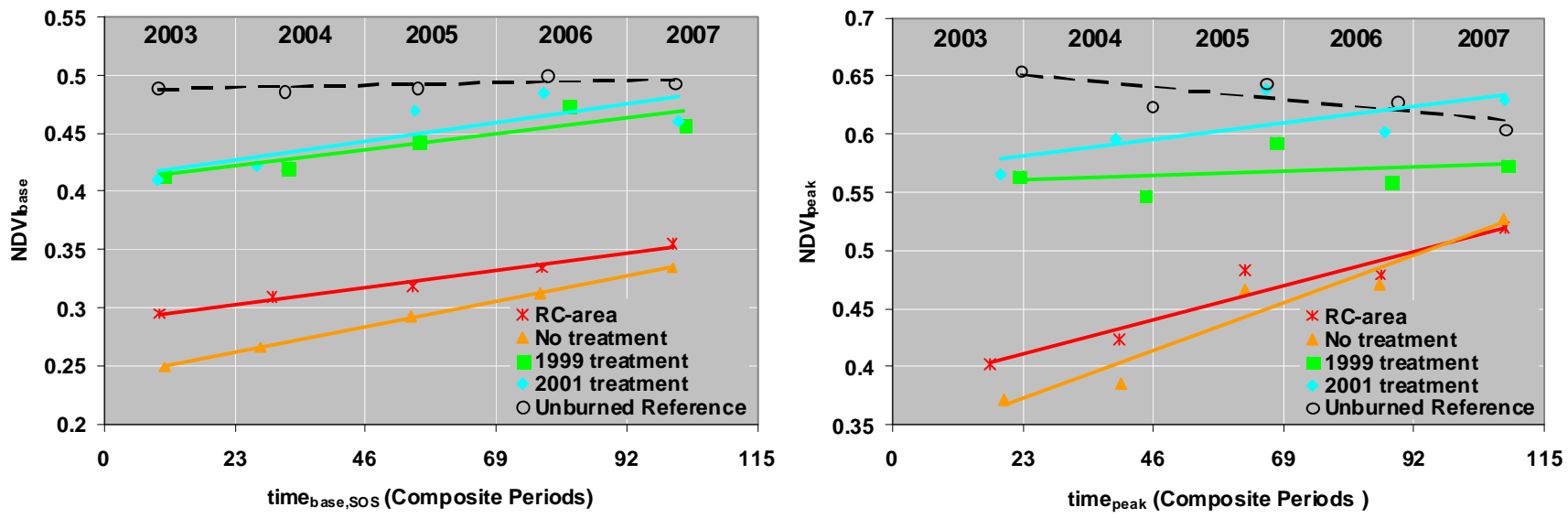

Pre-fire large integral values for all sites were very high, but dropped considerably during the drought and wildfire event in 2002. The large integral values for all fire affected sites seem (Figure16b) to follow the precipitation levels (Figure 2). The large integral values are low in 2002, but go up for the higher precipitation years (2003, 2004 and 2005) and go down again for 2006 and 2007. This suggests that the large integral is increasing with annual precipitation amounts. The drought period in 2002 reduced the large integral values in 2002 and 2003 for the reference site compared to 
the large integral value in 2001 and then stabilizes again in 2004, but at a lower level than in 2001. The large integral values for the treatment sites are more dynamic after the fire than the other sites, which might be attributed to the increased nutrient availability in the non-burned vegetation communities after the low severity ground fire at these sites.

Figure 16. NDVI based phenology metrics are shown for each site and each year for which the data were available. a) Small yearly integral, b) Large yearly integral, and c) Ratio of the left derivative (ld) and right derivative (rd).

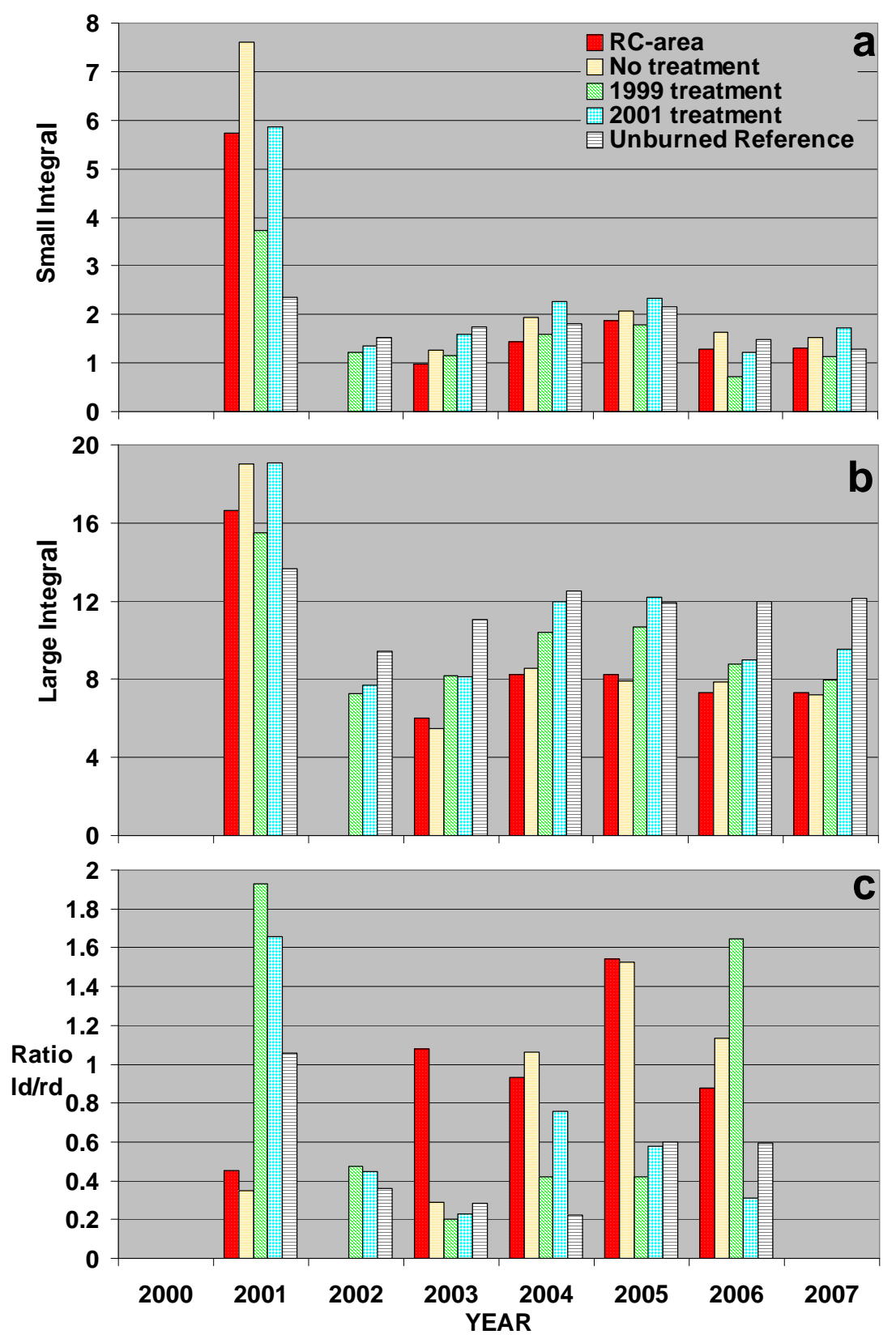

The ratio between green-up rate $(l d)$ and green-down rate $(r d)$ for the reference site is lower than 1 , which suggest that the green-up rate at the start of the season is lower than the green-down rate at the end of the season (Figure 16c). The $l d / r d$ ratio values are often higher for most of the fire affected sites than for the reference site, especially in 2004 and the following years, suggesting that the post-fire 
vegetation community at the sites might have changed and are responding differently to environmental conditions.

All the presented phenological metrics derived from the remotely sensed NDVI time-series data show promise, but varying degrees of applicability to the characterization of pre- and post-wildfire seasonal vegetation dynamics and evaluation of wildfire effects on fuel treatments and vegetation recovery. This exploratory study is somewhat confined by the limited data record length of the preand post-fire time series NDVI data from MODIS, since establishing good quality estimates of average and variability in pre-fire site conditions and post-fire response dynamics will benefit from a longer analysis period, which is clearly possible as MODIS continues to acquire data. Although the 16-day temporal resolution seems adequate to examine the interannual phenological changes and trends, higher temporal resolution data could potentially provide additional insights and some of the derived phenological metrics.

\section{Conclusions}

Remotely sensed data from both the Landsat and MODIS sensors were used to evaluate new ways to improve spatial and temporal measures of post-fire ecological response, characterize post-fire vegetation recovery, and evaluate the impact of prescribed burn restoration treatments. The Landsat based $\triangle$ NBR data were effectively used to classify the burn severity for the selected sites. The $\triangle$ NBR clearly showed that the unburned reference site was classified as unburned. The $\triangle \mathrm{NBR}$ for the sites where the prescribed-fire fuel treatments were applied in 1999 and 2001 indicated that these sites exhibited spatially distinct areas that were unburned or impacted by low severity burns.

Comparison of the MODIS NDVI time series data and trend analysis results between the complete Rodeo-Chediski site, an untreated site, the 1999 and 2001 prescribed fire treatment sites, and the unburned reference site, showed considerable increases in vegetation recovery rates with higher burn severity levels. A simple difference metric (i.e. difference form long term average) is an effective indicator of anomalies and amounts of change in the NDVI time-series data due to wildfire effects, but are less useful several years after the fire event. The sites with prescribed burn treatments exhibited much less change in these post-fire difference metrics than the untreated site.

The seasonality ratio (SR) between the NDVI values of the sites used in the analysis and the reference site effectively showed that the post-fire seasonality patterns for the fire affected sites changed with respect to the reference site. Some of these differences in seasonality could be related to climate variability, however the SR for the treated sites deviated the least from unity (10\% to $20 \%$ ), while the moderate to high severity sites deviated about $50 \%$ from the reference site. Therefore, there is evidence that the SR is a useful metric for evaluating the effectiveness of fuel treatments on vegetation recovery and seasonality. The temporal phase and amplitude shifts in the NDVI based SR also suggest successional changes in the composition of post fire vegetation communities.

Analysis of the annual NDVI based coefficients of variation for each site suggested that the spatial heterogeneity is highest during the year when the wildfire occurred and is gradually decreasing since the year of the fire. This initial exploration of characterizing ecosystem spatial heterogeneity in response to fire effects requires significant field data observations in future studies to better understand its implications for post-fire management efforts. 
Remotely sensed inter-annual phenological metrics were shown to be useful for characterizing preand post-wildfire seasonal vegetation dynamics and evaluating wildfire effects on fuel treatments and vegetation recovery. As with most wildfire events and associated research efforts, this exploratory study is based on a target of opportunity since this kind of catastrophic fire does not lend itself to carefully designing sampling protocols that allow for many years of data collection before and after the fire and treatments. Hence, as the data record length before and after the fire improves, longer term studies of the effect of fuel treatments and post-fire vegetation recovery in response to climate and fire effects will be possible. Nevertheless, many of the inter-annual phenological metrics that were derived from the NDVI time-series data show that they can be used to determine the effect of wildfire on ecological responses like the start and length of the growing season, trends in inter-annual values of the base and peak NDVI or greenness data that also provide measures of vegetation recovery rates, changes in rates of green-up and post season greenness decline, and vegetation productivity represented by the seasonal integration of NDVI values.

Remote sensing data and time-series analysis help to characterize fuels, vegetation, and fire effects before and after fires. This characterization of direct and long-term fire effects at local and regional scales is critical to understanding the impact of fuel reduction treatments and environmental factors on ecosystem processes. Clearly, this initial evaluation of these analysis procedures and new metrics provides the stimulus to conduct more research that directly compares these indices and analysis results to field data to better understand temporal and spatial patterns of post-fire ecosystem changes that are caused by interacting factors such as climate and fire and their effect on soils, canopy, and understory vegetation.

Remote sensing tools and technology are increasingly used to help with management and decision making responsibilities and uniquely expand on the often limited and costly acquisition of ground based data to address operational and applied research issues [40]. Web-based decision support tools could provide user communities with a capability to visualize, evaluate and analyze multi-temporal vegetation dynamics based on vegetation index data and run a time series animation of pre-fire and post-fire vegetation index and phenological data. Web-based remote sensing tools and technology will permit forest managers and other user and research communities to conduct historical analyses for planning and to develop forecasts of future ecological conditions in response to the effects of wildfire and prescribed fire restoration treatments in an environment of climate change and variability.

\section{Acknowledgements}

The author would like to thank Per Jönsson and Lars Eklundh for making the TIMESAT software available. Landsat and MODIS data are distributed by the Land Processes Distributed Active Archive Center (LP DAAC), located at USGS/EROS, Sioux Falls, SD. http://lpdaac.usgs.gov. The author also very much appreciates the help of his colleagues at the Arizona Remote Sensing Center, in particular Jennifer Davison and Grant Casady. The author is very grateful to Dr. Stuart E. Marsh for his suggestions for improving this manuscript. This research was inspired by several collaborative efforts, one of which was supported by a grant from the International Arid Lands Consortium (04R-02). 


\section{References}

1. Westerling, A. L.; Hidalgo, H. G.; Cayan, D. R.; Swetnam, T. W. Warming and earlier spring increase western US forest wildfire activity. Science 2006, 313, 940-943.

2. Finney, M.A.; McHugh, C.W.; Grenfell, I.C. Stand- and landscape-level effects of prescribed burning on two Arizona wildfires. Canadian Journal of Forest Research-Revue Canadienne de Recherche Forestiere 2005, 35, 1714-1722.

3. Idris, M.H.; Kuraji, K.; Suzuki, M. Evaluating vegetation recovery following large-scale forest fires in Borneo and northeastern China using multi-temporal NOAA/AVHRR images. Journal of Forest Research 2005, 10, 101-111.

4. Goetz, S.J.; Fiske, G.J.; Bunn, A.G. Using satellite time-series data sets to analyze fire disturbance and forest recovery across Canada. Remote Sensing of Environment 2006, 101, 352365 .

5. Lin, W.-T.; Chou, W.-C.; Lin, C.-Y.; Huang, P.-H.; Tsai, J.-S. Vegetation recovery monitoring and assessment at landslides caused by earthquake in Central Taiwan. Forest Ecology and Management 2005, 210, 55-66.

6. Tucker, C.J. Red and photographic infrared linear combinations for monitoring vegetation. Remote Sensing of Environment 1979, 8, 127-150.

7. Goward, S.N.; Tucker, C. J.; Dye, D. G. North American vegetation patterns observed with the NOAA-7 advanced very high resolution radiometer. Plant Ecology 1985, 64, 3-14.

8. Tucker, C.J.; Sellers, P. J. Satellite remote sensing of primary production. International Journal of Remote Sensing 1986, 7, 1395-1416.

9. Myneni, R.B.; Keeling, C.D.; Tucker, C.J.; Asrar, G.; Nemani, R.R. Increased plant growth in the northern high latitudes from 1981 to 1991. Nature 1997, 386, 698-702.

10. Tucker, C.J.; Slayback, D.A.; Pinzon, J.E.; Los, S.O.; Myneni, R.B.; Taylor, M.G. Higher northern latitude normalized difference vegetation index and growing season trends from 1982 to 1999. International Journal of Biometeorology 2001, 45, 184-190.

11. Huete, A.; Didan, K.; Miura, T.; Rodriguez, E.P.; Gao, X.; Ferreira, L.G. Overview of the radiometric and biophysical performance of the MODIS vegetation indices. Remote Sensing of Environment 2002, 83, 195-213.

12. Huete, A.R.; Didan, K.; Shimabukuro, Y.E.; Ratana, P.; Saleska, S.R.; Hutyra, L.R.; Yang, W.Z.; Nemani, R.R.; Myneni, R. Amazon rainforests green-up with sunlight in dry season. Geophysical Research Letters 2006, 33, 4.

13. Miller, J.D.; Yool, S.R. Mapping forest post-fire canopy consumption in several overstory types using multi-temporal Landsat TM and ETM data. Remote Sensing of Environment 2002, 82, 481496.

14. Epting, J.; Verbyla, D.; Sorbel, B. Evaluation of remotely sensed indices for assessing burn severity in interior Alaska using Landsat TM and ETM+. Remote Sensing Of Environment 2005, 96, 328-339.

15. Key, C.H.; Benson, N.C. Measuring and Remote sensing of burn severity. in U.S. Geological Survey Wildland Fire Workshop, Los Alamos, NM, 2000, 55. 
16. van Wagtendonk, J. W.; Root, R.R.; Key, C.H. Comparison of AVIRIS and Landsat ETM+ detection capabilities for burn severity. Remote Sensing of Environment 2004, 92, 397-408.

17. Key, C. H. Ecological and sampling constraints on defining landscape fire severity. Fire Ecology 2006, 2, 34-59.

18. Viedma, O.; Melia, J.; Segarra, D.; Garcia-Haro, J. Modeling rates of ecosystem recovery after fires by using landsat TM data. Remote Sensing of Environment 1997, 61, 383-398.

19. Diaz-Delgado, R.; Lloret, F.; Pons, X.; Terradas, J. Satellite Evidence of Decreasing Resilience in Mediterranean Plant Communities after Recurrent Wildfires. Ecology 2002, 83, 2293-2303.

20. Diaz-Delgado, R.; Lloret, F.; Pons, X. Influence of fire severity on plant regeneration by means of remote sensing imagery. International Journal of Remote Sensing 2003, 24, 1751-1763.

21. Riera, J.L.; Magnuson, J.J.; Vande Castle, J.R.; MacKenzie, M.D. Analysis of Large-Scale Spatial Heterogeneity in Vegetation Indices among North American Landscapes. Ecosystems 1998, 1, 268-282.

22. Barbosa, H.A.; Huete, A.R.; Baethgen, W.E. A 20-year study of NDVI variability over the Northeast Region of Brazil. Journal of Arid Environments 2006, 67, 288-307.

23. Weiss, E.; Marsh, S.E.; Pfirman, E.S. Application of NOAA-AVHRR NDVI time-series data to assess changes in Saudi Arabia's rangelands. International Journal of Remote Sensing 2001, 22, 1005-1027.

24. Reed, B.C.; White, M.A.; Brown, J.F. Remote sensing phenology. in Phenology: An Integrative Science, 2003, Shwartz, M. D., Ed.: Kluwer Publishing.

25. Lloyd, D. A Phenological Classification of Terrestrial Vegetation Using Shortwave Vegetation Index Imagery. International Journal of Remote Sensing 1991, 11, 2269-2279.

26. White, M.A.; Thornton, P.E.; Running, S.W. A continental phenology model for monitoring vegetation responses to interannual climatic variability. Global Biogeochemical Cycles 1997, 11, 217-234.

27. Badhwar, G.D. Use of LANDSAT-derived profile features for spring small-grains classification. International Journal of Remote Sensing 1984, 5, 783 - 797.

28. Moulin, S.; Kergoat, L.; Viovy, N.; Dedieu, G. Global-Scale Assessment of Vegetation Phenology Using NOAA/AVHRR Satellite Measurements. Journal of Climate 1997, 10, $1154-$ 1170.

29. Reed, B.C.; Brown, J.F.; Vanderzee, D.; Loveland, T.R.; Merchant, J.W.; Ohlen, D.O. Measuring Phenological Variability from Satellite Imagery. Journal of Vegetation Science 1994, 5, 703-714.

30. Zhang, X.; Friedl, M.A.; Schaaf, C.B.; Strahler, A.H.; Hodges, J.C.F.; Gao, F.; Reed, B.C.; Huete, A. Monitoring vegetation phenology using MODIS. Remote Sensing of Environment 2003, 84, 471-475.

31. Kaduk, J.; Heimann, M. Assessing the climate sensitivity of the global terrestrial carbon cycle model SILVAN. Physics and Chemistry of The Earth 1996, 21, 529-535.

32. Jönsson, P.; Eklundh, L. Seasonality extraction by function fitting to time-series of satellite sensor data. Geoscience and Remote Sensing, IEEE Transactions on 2002, 40, 1824-1832.

33. Jönsson, P.; Eklundh, L. TIMESAT--a program for analyzing time-series of satellite sensor data. Computers \& Geosciences 2004, 30, 833-845. 
34. Raymond, C.L.; Peterson, D.L. Fuel treatments alter the effects of wildfire in a mixed-evergreen forest, Oregon, USA. Canadian Journal of Forest Research-Revue Canadienne De Recherche Forestiere 2005, 35, 2981-2995.

35. Lowry, J.; Ramsey, R.D.; Thomas, K.; Schrupp, D.; Sajwaj, T.; Kirby, J.; Waller, E.; Schrader, S.; Falzarano, S.; Langs, L.; Manis, G.; Wallace, C.; Schulz, K.; Comer, P.; Pohs, K.; Rieth, W.; Velasquez, C.; Wolk, B.; Kepner, W.; Boykin, K.; O'Brien, L.; Bradford, D.; Thompson, B.; Prior-Magee, J. Mapping moderate-scale land-cover over very large geographic areas within a collaborative framework: A case study of the Southwest Regional Gap Analysis Project (SWReGAP). Remote Sensing of Environment 2007, 108, 59-73.

36. Eidenshink, J.; Schwind, B.; Brewer, K.; Zhu, Z.; Quayle, B.; Howard, S. A project for monitoring trends in burn severity. Fire Ecology 2007, 3, 3-21.

37. Key, C.H.; Benson, N.C. Landscape assessment-Remote sensing of severity, the Normalized Burn Ratio. USDA Forest Service Rocky Mountain Research Station, Ogden Utah, General Technical Report 2005.

38. Schoennagel, T.; Veblen, T.T.; Romme, W.H. The Interaction of Fire, Fuels, and Climate across Rocky Mountain Forests. BioScience 2004, 54, 661-676.

39. Pollet, J.; Omi, P.N. Effect of thinning and prescribed burning on crown fire severity in ponderosa pine forests. International Journal of Wildland Fire 2002, 11, 1-10.

40. Lentile, L.B.; Holden, Z.A.; Smith, A.M.S.; Falkowski, M.J.; Hudak, A.T.; Morgan, P.; Lewis, S.A.; Gessler, P.E.; Benson, N. C. Remote sensing techniques to assess active fire characteristics and post-fire effects. International Journal of Wildland Fire 2006, 15, 319-345.

(C) 2008 by MDPI (http://www.mdpi.org). Reproduction is permitted for noncommercial purposes. 